\title{
Metallasupramolecular architectures, an overview of functional properties and applications
}

\section{Catelijne H. M. Amijs, Gerard P. M. van Klink and Gerard van Koten*}

Received 15th April 2005, Accepted 1st July 2005

First published as an Advance Article on the web 7th September 2005

DOI: 10.1039/b505354d

The synthesis of metallasupramolecular architectures, such as two-dimensional squares, triangles and polygons, and three-dimensional cages and polyhedra, has attracted much interest in the past decade. These structures are designed to have novel specific shapes and dimensions with interesting functional properties. In this overview the functional properties of metallasupramolecular architectures are highlighted with emphasis on potential applications such as catalysis, cavity-directed synthesis and sensing, that can be performed with these materials.

\section{Introduction}

The term metallasupramolecular structures covers a broad range of metal-containing supramolecular structures. These compounds can be divided in different classes, e.g. metallo-dendrimers, ${ }^{1}$

Department of Organic Chemistry and Catalysis, Debye Institute, Utrecht University, Padualaan 8, $3584 \mathrm{CH}$, Utrecht, The Netherlands. E-mail: g.vankoten@chem.uu.nl; Fax:+31-30-2523615;Tel: +31-30-2533120 polymers and grids, ${ }^{2}$ and molecular cycles, boxes and cages. ${ }^{3}$ The latter class is often referred to as molecular architectures, as these structures are specifically designed to exhibit novel specific shapes and dimensions, for example two-dimensional squares, triangles and polygons and three-dimensional cages and polyhedra. ${ }^{3 a}$ Since the first report of a self-assembled metallasupramolecular square (1) in $1990,{ }^{4}$ the design of self-assembled molecular architectures has received considerable attention. ${ }^{3}$ Through directional coordinative bonding, two- and three-dimensional self-assemblies are

Catelijne Amijs obtained her PhD degree from Utrecht University in 2005, under the supervision of Professor van Koten. Her research was focused on the development of organo-platinum and-palladium building blocks for supramolecular assemblies. As of July 2005 she is a postdoctoral fellow at the Institute of Chemical Research of Catalonia (ICIQ) with Professor Echavarren.

Gerard van Klink obtained his PhD from the Vrije Universiteit, Amsterdam, under supervision of Professor Bickelhaupt on the mechanism of formation of organomagnesium compounds. He worked as a postdoctoral fellow on the design and synthesis of cocatalysts for Ziegler-Natta polymerization processes and on low-valent catalysts for olefin polymerization in the group of Prof. Eisch at the State University of New York at Binghamton, both in cooperation with DSM Research. Currently, he is working as a lecturer in the Organic Chemistry and Catalysis group of Prof. van Koten.

Gerard van Koten has been Professor of Organic Chemistry and Catalysis at the Debye Institute of the Utrecht University since 1986. In 2004 he became Distinguished Professor of the Utrecht University. In 2002 he has been appointed by the Minister of Education, Culture and Science as chairman of the committee responsible for the renewal of the Chemistry Educational Programme at the Secondary School level in the Netherlands. From 2005 on he acts as Dean of the Utrecht Faculty of Science. His research interests comprise the study of fundamental processes in organometallic chemistry and the application of organometallic complexes as homogeneous catalysts. The preparation and use of the first examples of homogeneous metallodendrimer catalysts demonstrate his interest in supramolecular systems with (organometallic) catalytically active functionalities. He is author of 692 papers and 23 patents.

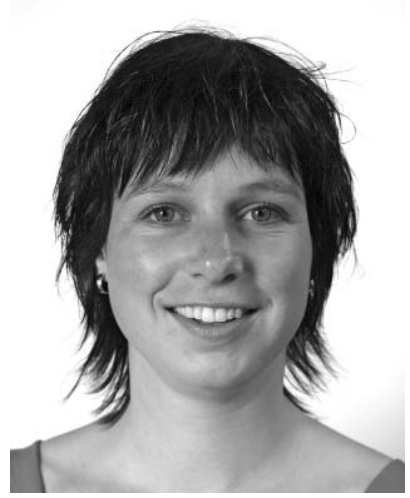

Catelijne H. M. Amijs

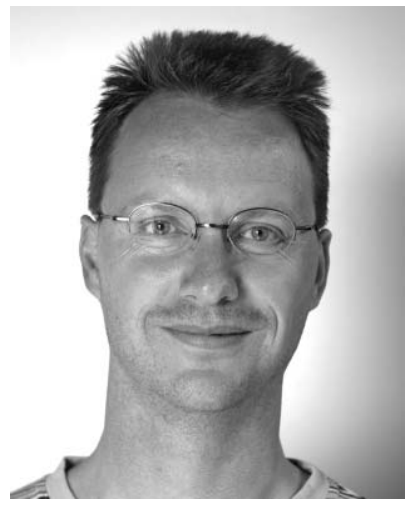

Gerard P. M. van Klink

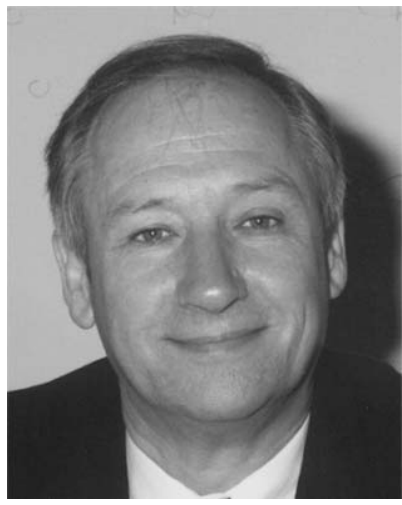

Gerard van Koten 
readily available by the spontaneous combination of electrondeficient metal centers with appropriate organic electron-donor ligands, such as Lewis bases.

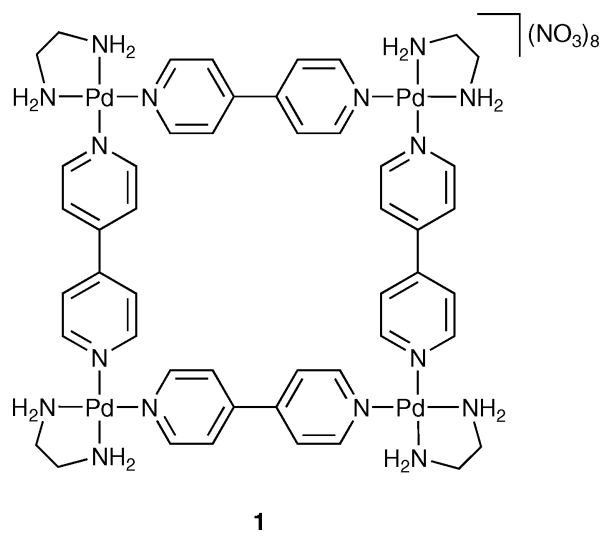

Some of these architectures display interesting functions and have potential applications in various fields, including host-guest chemistry, catalysis and photo- and electro-chemical sensing. Several excellent review articles on supramolecular coordination chemistry were focused on the design and preparation of metallamolecular architectures in which some coverage of functional properties is provided. ${ }^{3}$ However, only two recent reviews deal with these inherent functional properties: one specifically for metallamolecular squares, ${ }^{5 a}$ and one concise highlight on selfassembled molecular capsules. ${ }^{5 b}$ Significant progress has been made in the past few years in the rational design of functional supramolecular assemblies, but the interesting functional properties and applications of other metallasupramolecular architectures have not been reviewed yet.

Here, the functional properties of metallasupramolecular architectures are highlighted with a special emphasis on the potential applications, such as host-guest chemistry, cavity directed synthesis, homo- and hetero-geneous catalysis, photoluminescence, redox activity, magnetic behavior and photo- and electro-chemical sensing. Metallamolecular architectures that are not made via coordination chemistry, but contain stronger metal-carbon $\sigma$ bonds, are also included.

\section{Functional properties}

The attractive features of metallasupramolecular architectures are their functional properties and potential use for various applications. The formation of these architectures via straightforward self-assembly reactions has several advantages. Firstly, functionalities can readily be introduced onto the metallasupramolecular structures by employing functional ligands and/or metal centers in the assembly process. Upon formation of the superstructures, these centers may interact, thus leading to a higher level of functionality and the cavities that are created this way may accommodate guest molecules. Secondly, macrocycles and cages containing transition metals are generally more sensitive and responsive to electro- and photo-chemical stimuli compared to the metal-free organic structures. The most important properties, which arise upon formation of these architectures, include encapsulation of guest molecules, luminescence and redox activity. These functional properties are addressed below in more detail.

\subsection{Encapsulation of guest molecules}

As mentioned above, the self-assembly of supramolecular structures can lead to the formation of architectures which contain sizeable cavities. Depending on the size of the cavities, these structures can act as hosts for various guest molecules. Often, solvent molecules or anions reside in these holes, but numerous reports have shown that these molecules can readily be replaced by other guest compounds. For this behavior, expressions as encapsulation, host-guest chemistry and molecular recognition are being used in the literature. In this sense, the term recognition is not always properly used, as recognition implies awareness of the host for a specific guest. Indeed, various hosts were found to have a greater affinity for a particular (type of) guest. However, the term recognition implies more than just affinity and, therefore, we chose not to use this expression. In paragraph 3.2, Sensing, we will focus more on recognition in terms of sensing applications.

The first investigation on the binding properties of a metallamacrocycle toward small organic molecules has been reported by Maverick et al. in $1986 .^{6}$ They compared binding constants for the dinuclear copper(II) cycle 2 (Fig. 1) with mono- or difunctional Lewis bases such as pyridine $\left(K_{\mathrm{a}}=0.5 \mathrm{M}^{-1}\right)$, quinuclidine $\left(K_{\mathrm{a}}=\right.$ $\left.7 \mathrm{M}^{-1}\right)$, pyrazine $\left(K_{\mathrm{a}}=5 \mathrm{M}^{-1}\right)$ and dabco $\left(K_{\mathrm{a}}=220 \mathrm{M}^{-1}\right)$ in $\mathrm{CHCl}_{3}$ solutions, and concluded that the larger constants for the potentially bidentate coordinating compounds were consistent with internal coordination in the cavity.

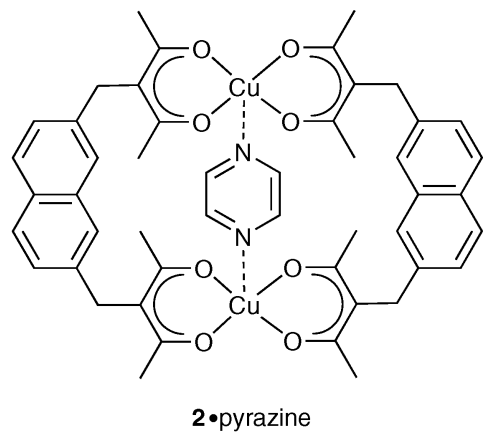

Guest molecules

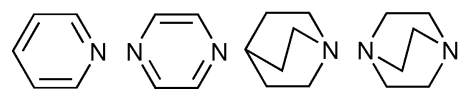

Fig. 1 Metallacycle 2.pyrazine and various guest molecules.

Larger, more complex organic molecules were bound by molecular bowls and cages. For example, self-assembled cadmiumand zinc-based resorcarene-based loops were found to be able to encapsulate $\mathrm{C}_{60}$ in a $1: 1$ host : guest ratio. ${ }^{7}$ Another interesting example is the molecular bowl 3 (Fig. 2), which contains a zincporphyrin unit that is able to bind amines. ${ }^{8}$ The four cholates with potentially binding hydroxyl groups are able to direct the binding of guests into the cavity. The binding constants of codeine methyl ether, codeine and morphine, were compared to free zincporphyrin and an increase in binding constant was found $\left(K_{\mathrm{a}}=\right.$ $240,13 \times 10^{3}$ and $23 \times 10^{4} \mathrm{M}^{-1}$, respectively, compared to the values found for free porphyrin $K_{\mathrm{a}}=170,110$ and 60, respectively). Size discrimination became evident for the binding properties of larger alkaloids, brucine and strychnine, which could not enter the 


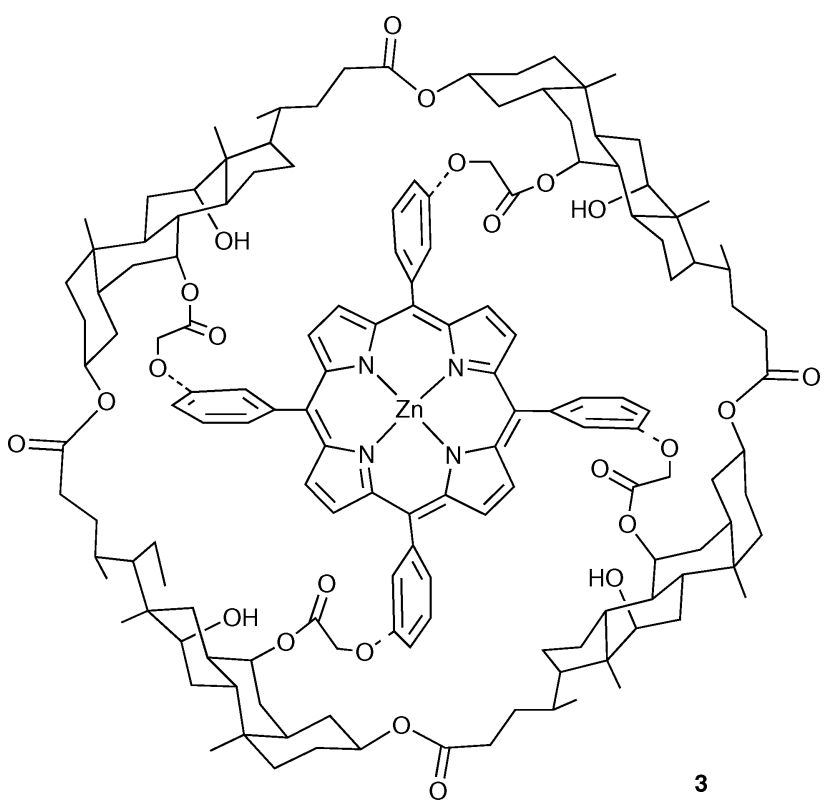

Guest molecules

Morphine

Codeine

Codeine methyl ether

$\mathrm{N}$-methylpiperidine

Pyridine

Fig. 2 Molecular bowl 3 and guest molecules.

bowl and thus interacted with the outside face of the porphyrin moiety.

The discrimination of size upon encapsulation was also reported by Chen et al. ${ }^{9}$ The two neutral platinum(II) cyclophanes 4 and 5 (Fig. 3), were able to complex mono- and di-saccharides in a $1: 1$ binding stoichiometry. Complex 4 displayed a greater binding ability toward saccharides than $\mathbf{5}$, which was ascribed to its larger cavity. The cyclophanes both exhibited a greater binding affinity for the disaccharides than for the monosaccharides $\left(4: K_{\mathrm{a}}=\sim 2 \times\right.$ $10^{3}$ and $4 \times 10^{4} \mathrm{M}^{-1}, \mathbf{5}: K_{\mathrm{a}}=\sim 8 \times 10^{2}$ and $8 \times 10^{3} \mathrm{M}^{-1}$, for mono- and di-saccharides, respectively), which suggests that the $\mathrm{OH}$ groups of the longer disaccharides could also bind the ether oxygen or amide nitrogens. More examples of size discrimination for organic guests are also reported for self-assembled osmium ${ }^{10}$ or palladium ${ }^{11}$ cycles.

Jeong and co-workers reported a self-assembled cationic palladiamacrocycle (6, Fig. 4), which also acted as a host for organic molecules. ${ }^{12}$ Generally, the cavities of cationic hosts are filled either with counter anions or with solvent molecules with the anion residing outside the cavity. ${ }^{3}$ The large 70 -membered cycle 6 , however, which was folded to generate two subcavities, was found to be able to accommodate in each cavity in a cooperative manner an $N, N, N^{\prime}, N^{\prime}$-tetramethylterephthalamide (G1) guest molecule that has the appropriate size, shape and functionality. The macrocycle showed a high homotropic cooperative binding in a $1: 2$ host-guest ratio, i.e. $K_{\mathrm{a} 2}>K_{\mathrm{a} 1}\left(K_{\mathrm{a} 1}=180 \mathrm{M}^{-1}\right.$ and $\left.K_{\mathrm{a} 2}=450 \mathrm{M}^{-1}\right)$.

With the paramagnetic self-assembled tetranuclear iron(II) and cobalt(II) resorc[4]arene cage complexes 7 and $\mathbf{8}$ (Fig. 5), Harrison and co-workers demonstrated the reversible $\mathrm{pH}$-dependent encapsulation of various organic guest molecules, and their use as NMR shift reagents. ${ }^{13}$ The anionic complexes were capable of binding organic molecules that did not contain metal-binding atoms in host : guest ratios ranging from $1: 1$ to $1: 4$. For cage 8 the ${ }^{1} \mathrm{H}$ NMR signals of the encapsulated guests had large upfield shifts (30-40 ppm) with respect to the empty cage. The chemical shifts of a wide range of guest molecules were similar with respect to each other, and therefore the cage could function as an NMR shift reagent for included guests. The guests could easily be removed by lowering the $\mathrm{pH}$, as this broke the metal-ligand coordination and yielded the free guest and host ligand.

Since their report on the first self-assembled square $1,{ }^{4}$ Fujita and co-workers have reported the self-assembly of various cationic palladium(II) and platinum(II) molecular squares, cycles, bowls and cages. ${ }^{3 b}$ Most of these complexes, for example molecular

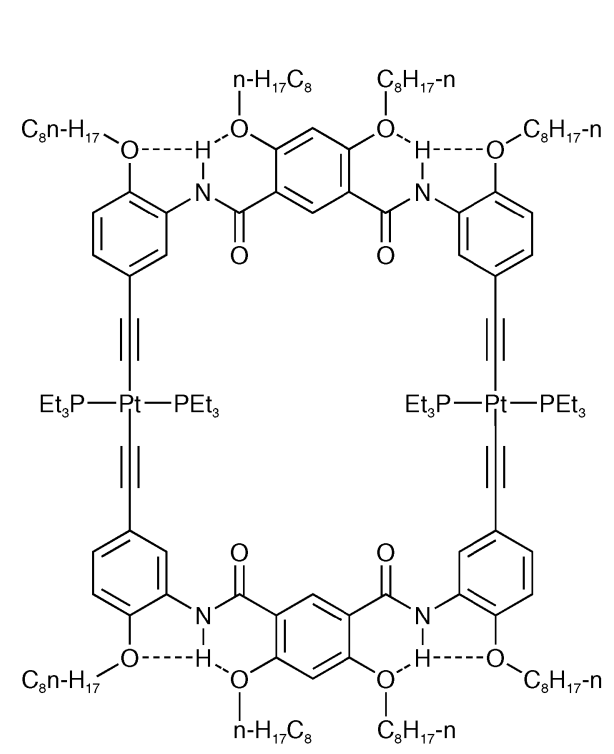

4

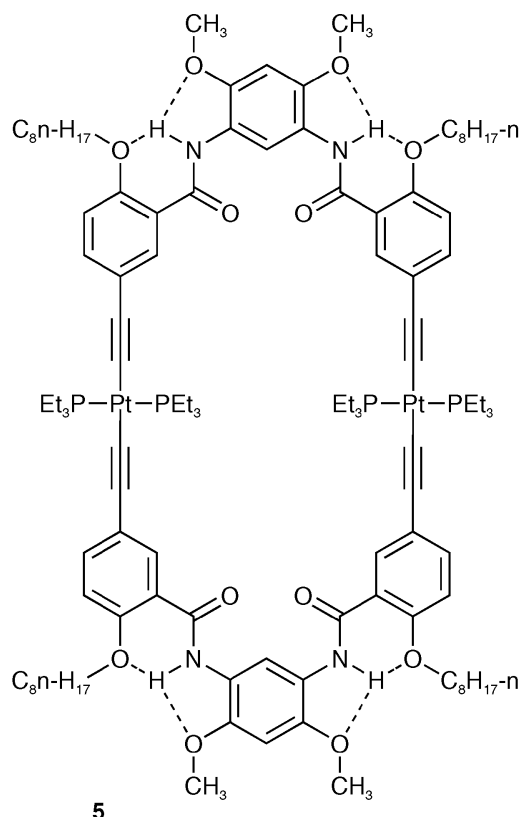

Guests molecules

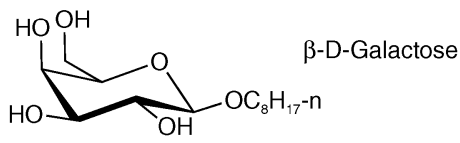<smiles>OC[14CH2]OC1[C@H]([18OH])O[C@H](CO)[C@H]1O</smiles>

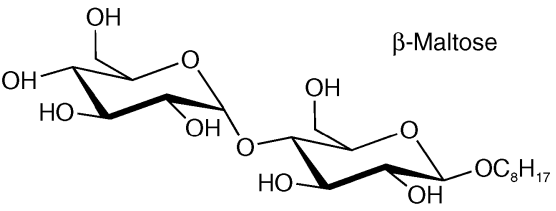

Fig. 3 Platinum cyclophanes $\mathbf{4}$ and $\mathbf{5}$ with guest molecules. 


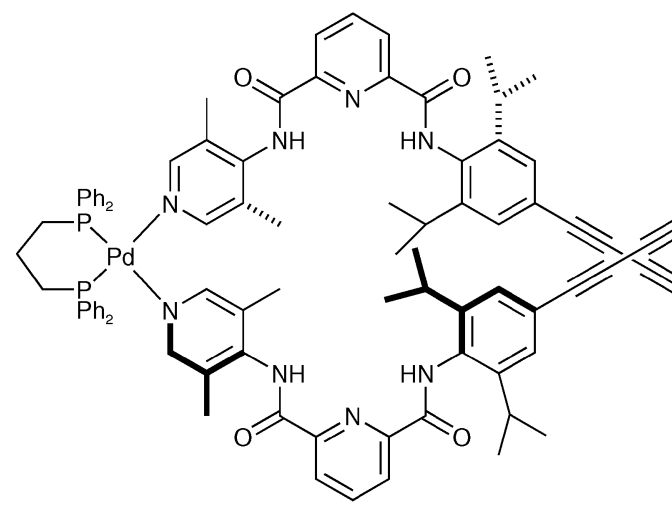

6

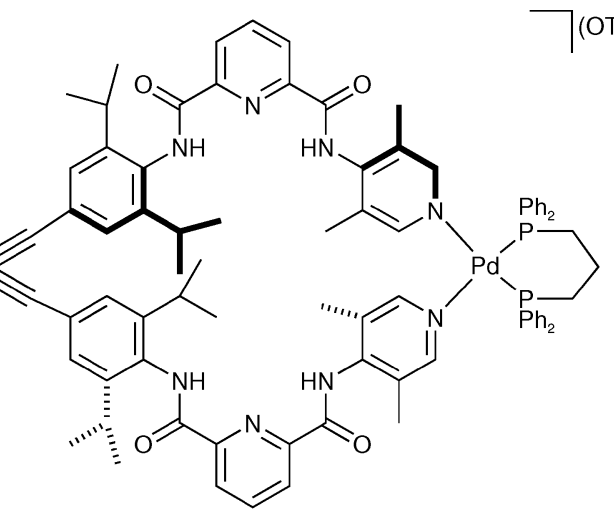

Encapsulation reaction

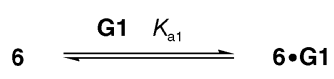

Guest<smiles>CNC(=O)c1ccc(C(=O)NC)cc1</smiles>

G1

Fig. 4 Folded metallacycle 6 with guest molecule and encapsulation reaction.

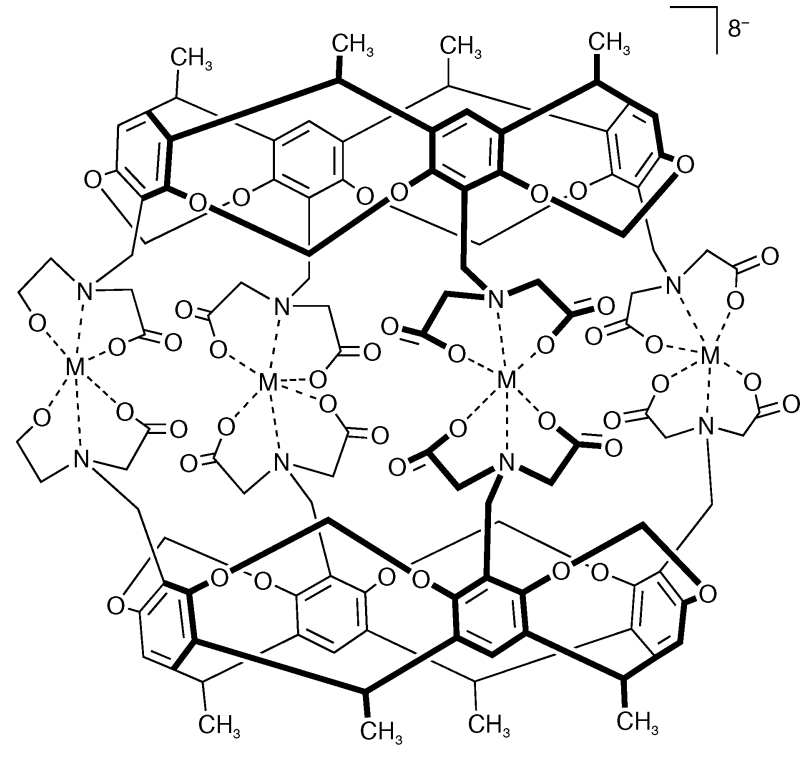

Guests

$$
\mathrm{M}=\mathrm{Fe}^{\prime \prime}(7), \mathrm{Co}^{\prime \prime}(\mathbf{8})
$$

Aromatic compounds Alkanes and alkenes Alcohols Haloalkanes

Fig. 5 Cages 7 and 8 and their guest molecules.

squares 1 and 9 (Fig. 6), ${ }^{14}$ have cavities large enough to accommodate small organic molecules. Complexation of non-anionic guests by these compounds occurred via interactions in the cavities (charge-transfer interactions as well as hydrophobic interaction between electron-deficient pyridine nuclei and electron-rich aromatic guests). Aromatic guests were preferred over aliphatic guests. In addition to these complexes, molecular cage $\mathbf{1 0}$ with a +24 charge (Fig. 6), could even host one cationic guest molecule $\mathrm{NBu}_{4}{ }^{+}$, upon exposure to an excess of $\left[\mathrm{NBu}_{4}\right]\left(\mathrm{BF}_{4}\right) .{ }^{15}$ The host-guest complex could be seen as a triple-layer onion-like structure, in which an anionic sphere of $\mathrm{BF}_{4}{ }^{-}$ions is mediated between cationic host and guest. No encapsulation was observed in absence of $\mathrm{BF}_{4}{ }^{-}$, indicating a clear role of the anion in the encapsulation process.
Fujita also reported bowl 11 and cage 12 (Fig. 7), which are amphiphilic in nature. ${ }^{16}$ The hydrophobic cavities are surrounded by aromatic rings, whereas the outside surfaces are electrophilic due to exposure of six cationic charged $\mathrm{Pd}^{\mathrm{II}}$ centers. In the solid state the molecular bowl $\mathbf{1 1}$ assembled into a dimeric capsule, which accommodated two terphenyl or six cis-stilbene molecules within the large hydrophobic pocket. ${ }^{16 a}$ Molecular cage 12 was able to encapsulate four guest molecules of either $o$-carborane or 1,3,5trimethoxybenzene, but electron-deficient molecules 1,4-dibromo-, 1,3,5-tribromo- and perfluoro-benzene were not complexed. ${ }^{16 b}$ This demonstrated that the interior of the cage creates a hydrophobic as well as an electrophilic microspace with properties different from the bulk phase. In a recent communication Fujita and coworkers demonstrated a sequence-selective recognition of peptides by the binding pocket of cage 12 by $\pi-\pi$ stacking. ${ }^{17}$ It was also reported that cage $\mathbf{1 2}$ could be used for the electrochemicallydriven clathration/declathration of ferrocene $(\mathrm{Fc})$ derivatives in a $1: 4$ host : guest ratio. ${ }^{18}$ The peak currents of the $\mathrm{CV}$ measurements were greatly enhanced by the encapsulation of ferrocene, caused by higher effective concentration within the cavity. Bulk electrolysis measurements showed that the encapsulated ferrocene guests left the cage after they were electrochemically oxidized to $\mathrm{Fc}^{+}$.

The encapsulation of cationic metal complexes was achieved by Hupp and co-workers, who reported that molecular square $13(\operatorname{Re} \cdots \operatorname{Re}=20 \AA$, Fig. 8$)$ was able to bind various guests such as small organic molecules (hydroquinone and nitrobenzene), small main-group ions $\left(\mathrm{I}^{-}(2.4 \AA)\right)$ and small and intermediate size metal complexes $\left(\mathrm{FcCH}_{2} \mathrm{OH}(4.5 \AA),\left[\mathrm{Fe}(\mathrm{CN})_{6}\right]^{3+}(6.0 \AA)\right.$, $\left[\mathrm{Ru}\left(\mathrm{NH}_{3}\right)_{5}(4 \text {-picoline })\right]^{2+}(6.7 \AA)$ and $\left[\mathrm{Co}(\mathrm{bpy})_{3}\right]^{2+}(11 \AA) .{ }^{19}$ Thin films of the molecular squares were made by evaporation of a solution of $\mathbf{1 3}$ at the surface of an electrode, after which the films were exposed to an aqueous solution of an electroactive probe molecule. The films were impermeable to $\left[\mathrm{Fe}\left(\mathrm{bphenSO}_{3}\right)_{3}\right]^{4-}$ (24 $\AA$, bphen $\mathrm{SO}_{3}=$ disulfonated bathophenanthroline). Also by modification of the cavities, size-dependent encapsulation was achieved. Modification of the squares was done by encapsulation of porphyrins that bonded either two-point (14) or four-point (15). This resulted in the formation of two cavities $(20 \times 10 \AA)$ or four small cavities ( $6 \AA$ ), respectively. The smaller cavities only allowed permeation of $\mathrm{I}^{-}$, while the larger cavities encapsulated species 


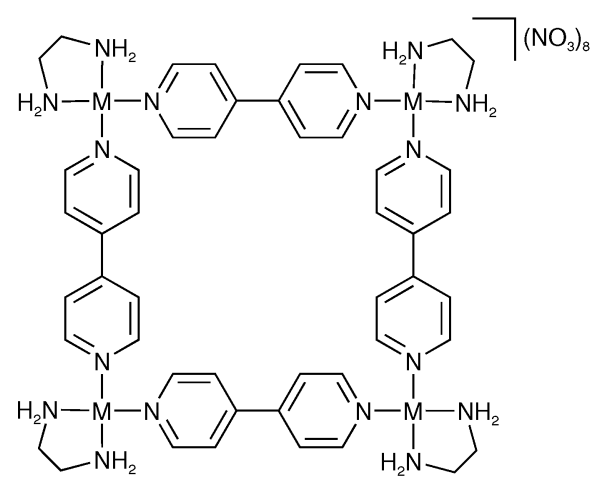

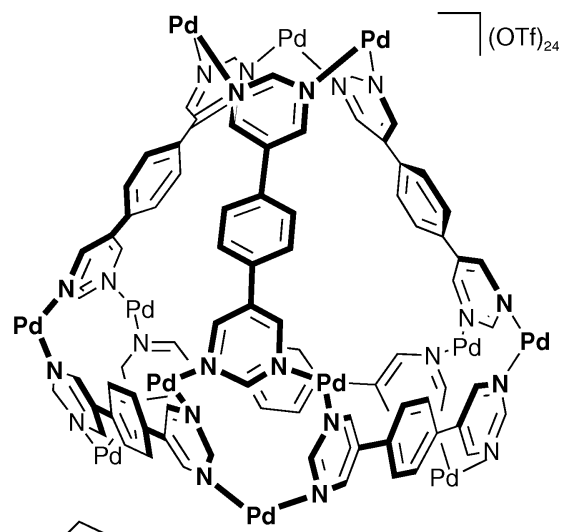

$M=\operatorname{Pd}(1)$

Pt (9)

$P d=$

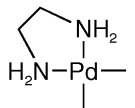

10

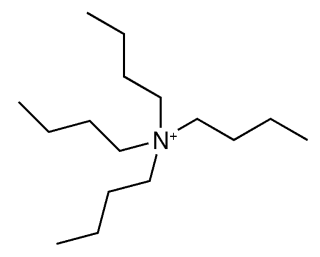

Fig. 6 Hosts 1,9 and 10 and their guest molecules.

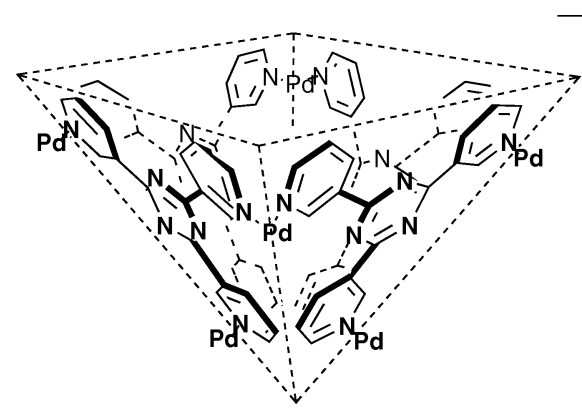

11

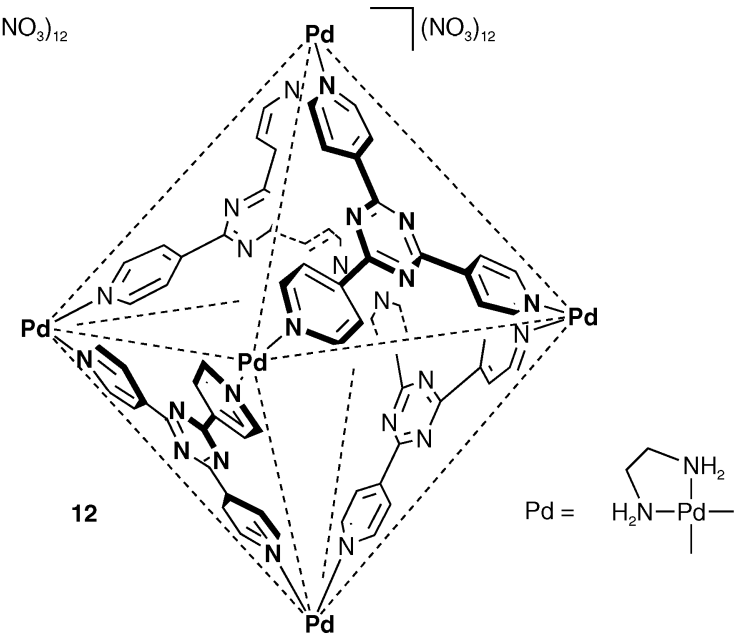

Guests
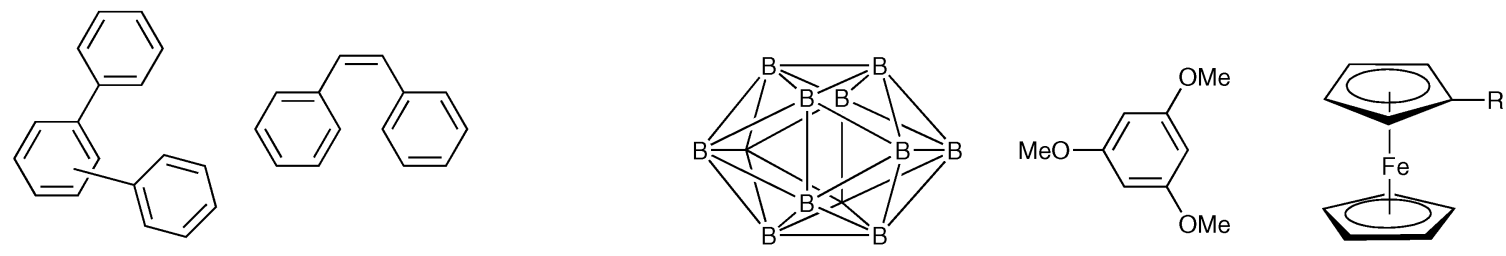

$8 \AA$

Fig. 7 Hosts $\mathbf{1 1}$ and $\mathbf{1 2}$ and their guest molecules.

such as $\left[\mathrm{Ru}\left(\mathrm{NH}_{3}\right)_{6}\right]^{2+}$ and ferrocenylmethanol, but not the larger $\left[\mathrm{Co}(\mathrm{bpy})_{3}\right]^{2+}$ entity.

Stang and co-workers encapsulated two silver triflate molecules in the self-assembled molecular square 16 (Fig. 9) via bonding to the ethynyl groups. ${ }^{20}$ Even with the clathrated silver complexes present, the cavity was still large enough to accommodate additional bidentate coordinating Lewis bases in a $1: 1$ host-guest ratio
( $1: 2$ in the case of monodentate coordinating pyridine). In these cases the silver complexes acted as receptors for the nitrogen-based guests.

The chiral tetranuclear cage 17 (Fig. 10), a pyramidal $\left(\mathrm{Ga}^{3+}\right)_{4}$ structure with six 1,5-bis(2',3'-dihydroxybenzamido)naphthalene ligands from Raymond and co-workers, was also able to encapsulate cationic organometallic guests in the hydrophobic cavity, viz. 


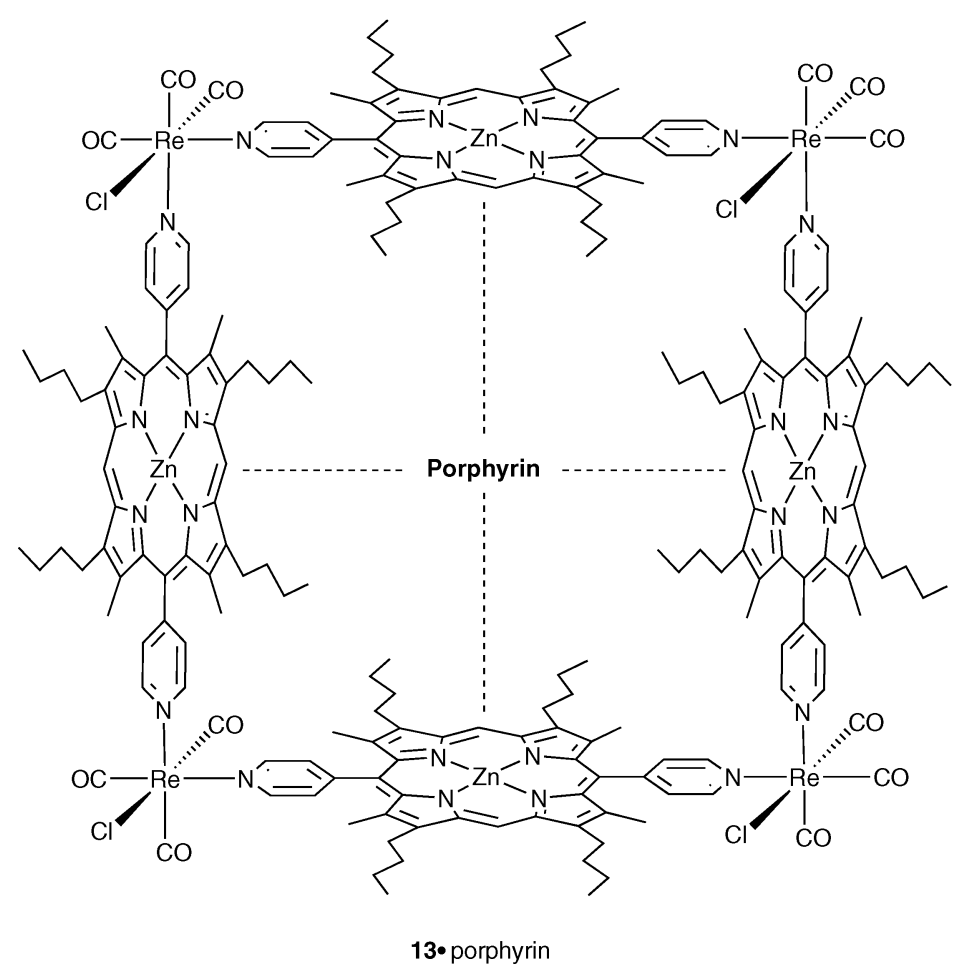

Guests

$\mathrm{I}^{-}, \mathrm{FcCH}{ }_{2} \mathrm{OH},\left[\mathrm{Fc}(\mathrm{CN})_{6}\right]_{3}^{-},\left[\mathrm{Re}\left(\mathrm{NH}_{3}\right)_{5}(4-\text { picoline })\right]^{2+}$, $\left[\mathrm{M}(\mathrm{bipy})_{3}\right]^{2+}(\mathrm{M}=\mathrm{Co}, \mathrm{Fe})$

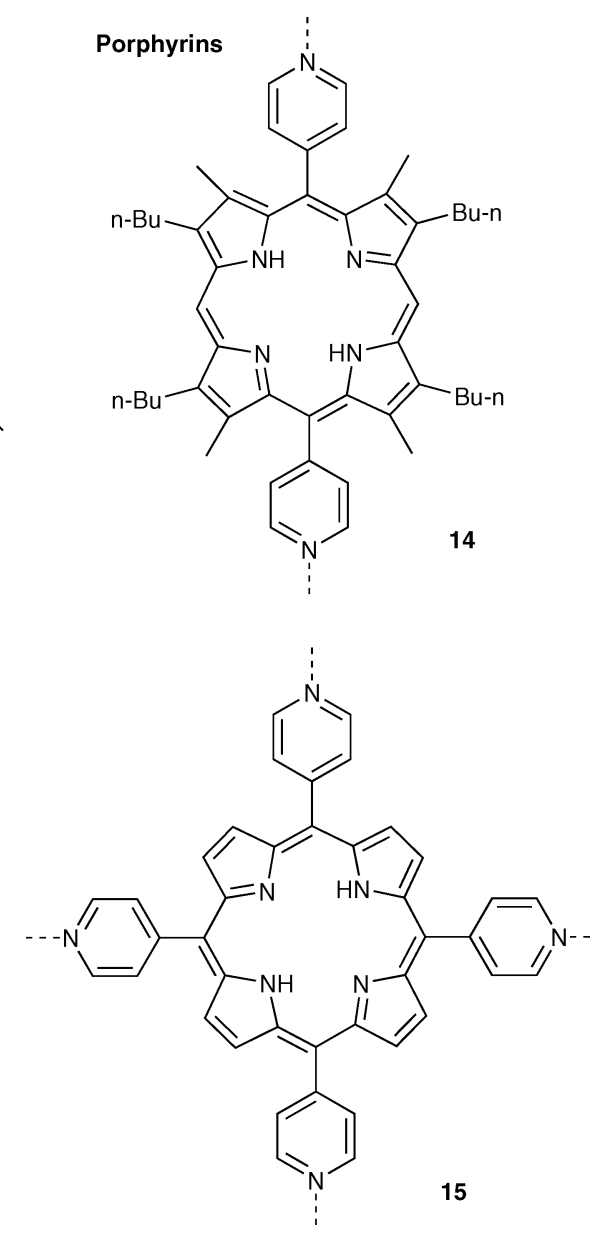

Fig. 8 Host 13 with encapsulated porphyrins 14 and 15 and the guest molecules.

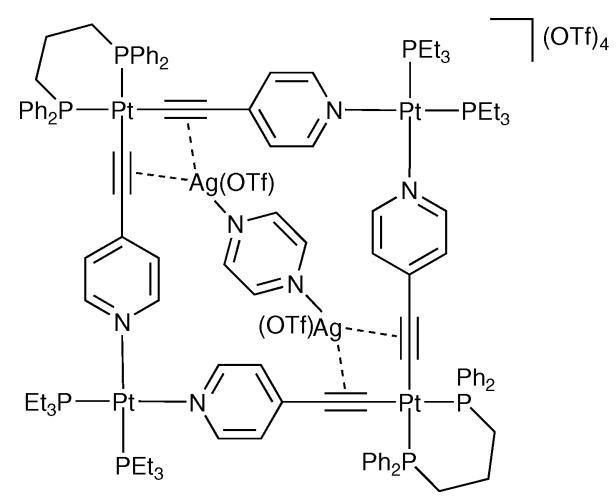

16(AgOTf $)_{2} \bullet$ pyrazine<smiles>O=C(c1ccncc1)c1ccncc1</smiles>

Fig. 9 Self-assembled square 16 with encapsulated [AgOTf] and its guest molecules.
$\left[\mathrm{CpRu}\left(\eta^{6}-\mathrm{C}_{6} \mathrm{H}_{6}\right)\right]^{+}(\mathbf{G} 2)$ and prochiral $[\mathrm{CpRu}(p \text {-cymene })]^{+}(\mathbf{G} 3){ }^{21}$ Upon encapsulation of a racemic mixture of the chiral complex $\left[\mathrm{Cp} * \mathrm{Ru} \text { (butadiene) }\left(\mathrm{H}_{2} \mathrm{O}\right)\right]^{+}$(G4) two diastereomeric host-guest complexes [G4 $\subset \mathbf{1 7}$ ] were formed. ${ }^{22}$ Depending on the $\mathrm{R}$ substituents, a diastereomeric excess (de) up to $70 \%$ was observed, i.e. the host preferred one enantiomer of the chiral guest complex over the other, with the higher selectivity reflecting the guest molecule's close fit into the cavity. This encapsulation reaction is, therefore, an example of a dynamic resolution of enantiomers.

Another interesting feature of $\mathbf{1 7}$ was the cavity directed reaction between with ketones (acetone, methyl ethyl ketone, fluoroacetones) and phosphines ( $\left.\mathrm{PMe}_{3}, \mathrm{PEt}_{3}, \mathrm{PPhMe}_{2}, \mathrm{PPh}_{2} \mathrm{Me}\right)$ in the presence of protons, which led to the encapsulation and stabilization of the thus formed reactive species $\left[\mathrm{R}^{\prime} \mathrm{MeC}(\mathrm{OH}) \mathrm{PR}_{3}\right]^{+}{ }^{23}$ The trapping of these specific reactive compounds had never been observed before, as they normally decompose in aqueous solution. The stabilization was dependent on size and nature of the guests, i.e. smaller adducts $\left(\mathrm{R}^{\prime}=\mathrm{Me}\right)$ were less stable, while aromatic groups in $\mathrm{PPhMe}_{2}$ with the potential for $\pi$-stacking with the naphthalene rings in $\mathbf{1 7}$, contributed to its stability.

The capability of encapsulation of the large range of guest molecules by the described metallasupramolecular structures has potential applications in the field of stabilizing (as described above), cavity-directed synthesis, catalysis and sensing. This will be discussed further in paragraph 3 . 

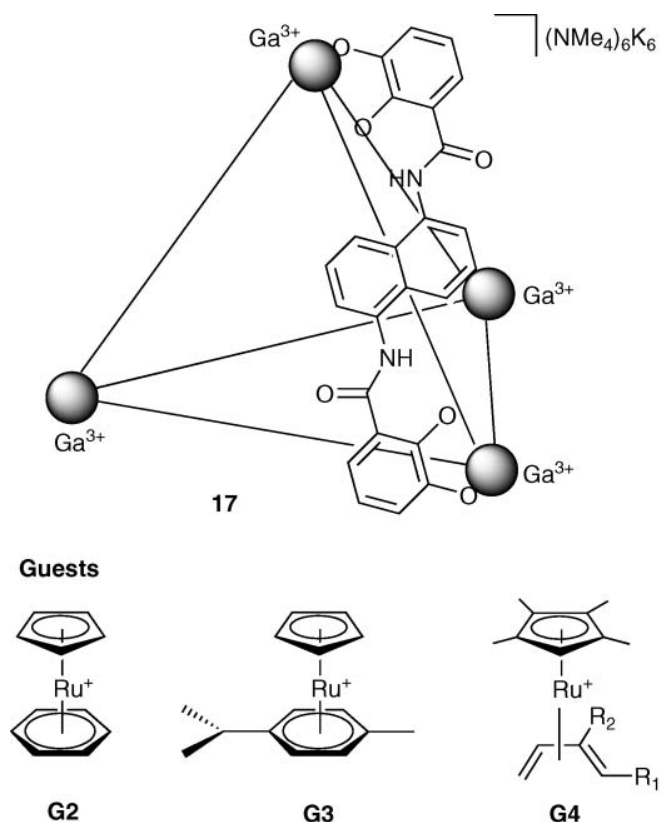

$\mathrm{R}=\mathrm{H}, \mathrm{Me} . \mathrm{Et}, n-\mathrm{Pr}, i-\mathrm{Pr}$

Reaction

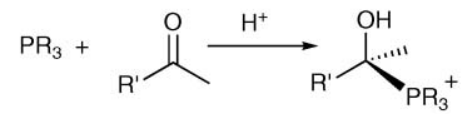

$\mathrm{PR}_{3}=\mathrm{PMe}_{3}, \mathrm{PEt}_{3}, \mathrm{PPhMe}_{2}, \mathrm{PPh}_{2} \mathrm{Me}$

$\mathrm{R}^{\prime}=\mathrm{Me}, \mathrm{Et}, \mathrm{CFH}_{2}, \mathrm{CF}_{3}$

Fig. 10 Molecular cage 17, its guest molecules and the cage-stabilized reaction of phosphines with ketones.

\subsection{Photoluminescence}

Although the photoluminescence of some photoactive building blocks such as porphyrins, was diminished or quenched completely upon metal coordination, ${ }^{24}$ conserved persistence or even enhancement of luminescence upon complexation to supramolecular structures was also observed. ${ }^{25}$ In the literature various luminescent metallasupramolecular architectures have been reported, of which rhenium-based self-assembled molecular squares ${ }^{26}$ and rectangles ${ }^{27}$ occur most frequently. Examples are the molecular square 18 and triangle 19 from Lees and co-workers, which both exhibited luminescence in solution at room temperature. ${ }^{28}$ Similar structures, 20, 21 and 22 were reported by Hupp and co-workers. ${ }^{29}$

These squares were also luminescent at room temperature, which makes these complexes potentially useful as small-molecule sensors (see paragraph 3.2, where the use of $\mathbf{2 0}$ and $\mathbf{2 1}$ as sensor materials is described). Related molecular squares $\mathbf{2 3}$ and $\mathbf{2 4}$ with $\mathrm{Zn}^{\mathrm{II}}$-salen species $\mathbf{2 5}$ as bridging ligands were found to be moderately fluorescent at room temperature as well (Fig. 11). ${ }^{30}$ It was, however, found that the emissive excited-state lifetimes ( $\tau$ ) of 20-24 are significantly shorter for the squares than for the corresponding monomeric corner complexes. A possible explanation for the shortened lifetimes was an intramolecular quenching effect of the excited states by further charge transfer to proximal chromophores. More importantly, similar to complex 13. complexes 23 and $\mathbf{2 4}$ could encapsulate one $\mathrm{Zn}^{\mathrm{II}}$-salen molecule 25b and 25a, respectively, in the cavity by pyridyl-to-zinc coordination $\left(K_{\mathrm{a}}=9 \times 10^{4} \mathrm{M}^{-1}\right)($ Fig. 11$) .{ }^{30}$ Photoexcitation of the hostguest complex $\mathbf{2 3} \cdot \mathbf{2 5} \mathrm{b}$ resulted in fluorescence exclusively from the square, with higher emission intensity in comparison to the host complex. This is indicative for efficient energy transfer (EnT) from the guest $\mathrm{Zn}^{\mathrm{II}}$-salen to the surrounding square (EnT rate constant $>10^{-10} \mathrm{~s}^{-1}$ ). Depending on the backbone of the salen complex
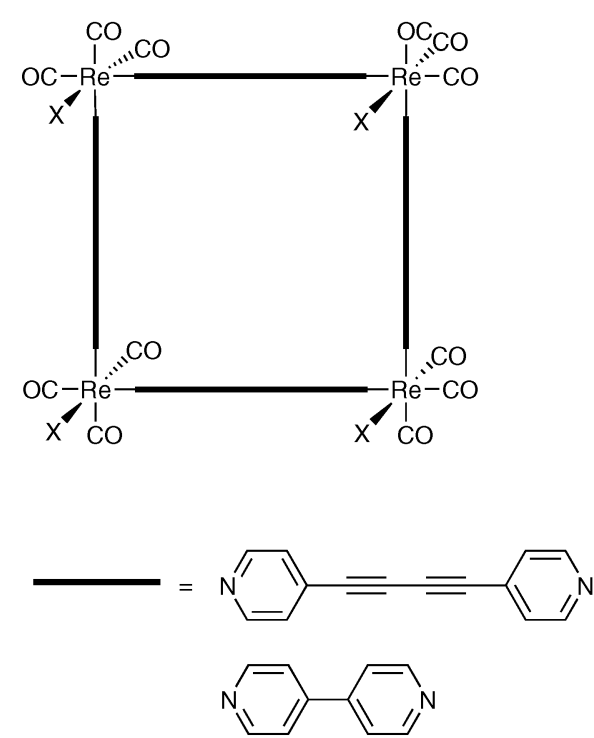<smiles>c1cnccn1</smiles>

20

21

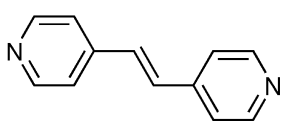

22

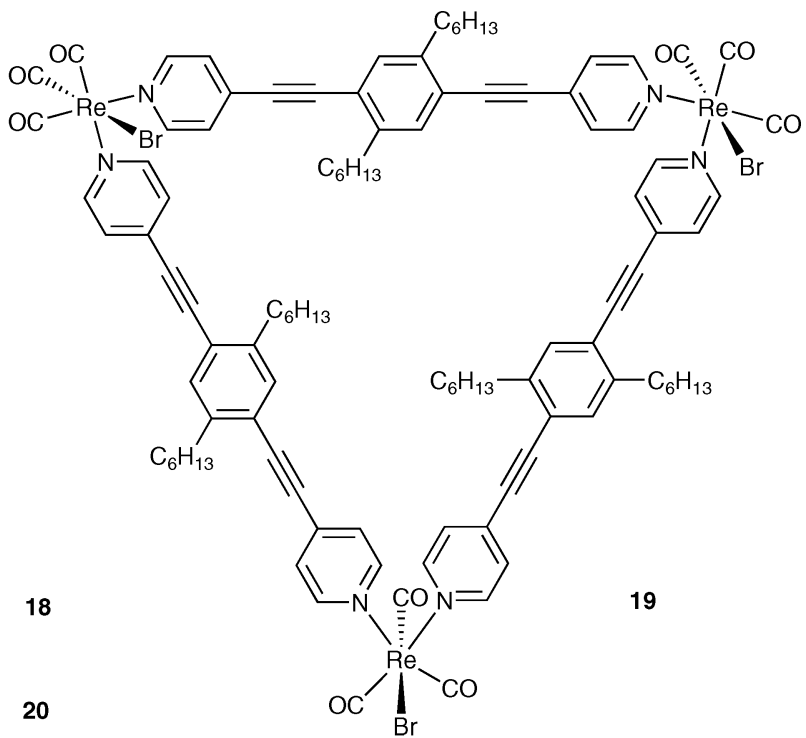




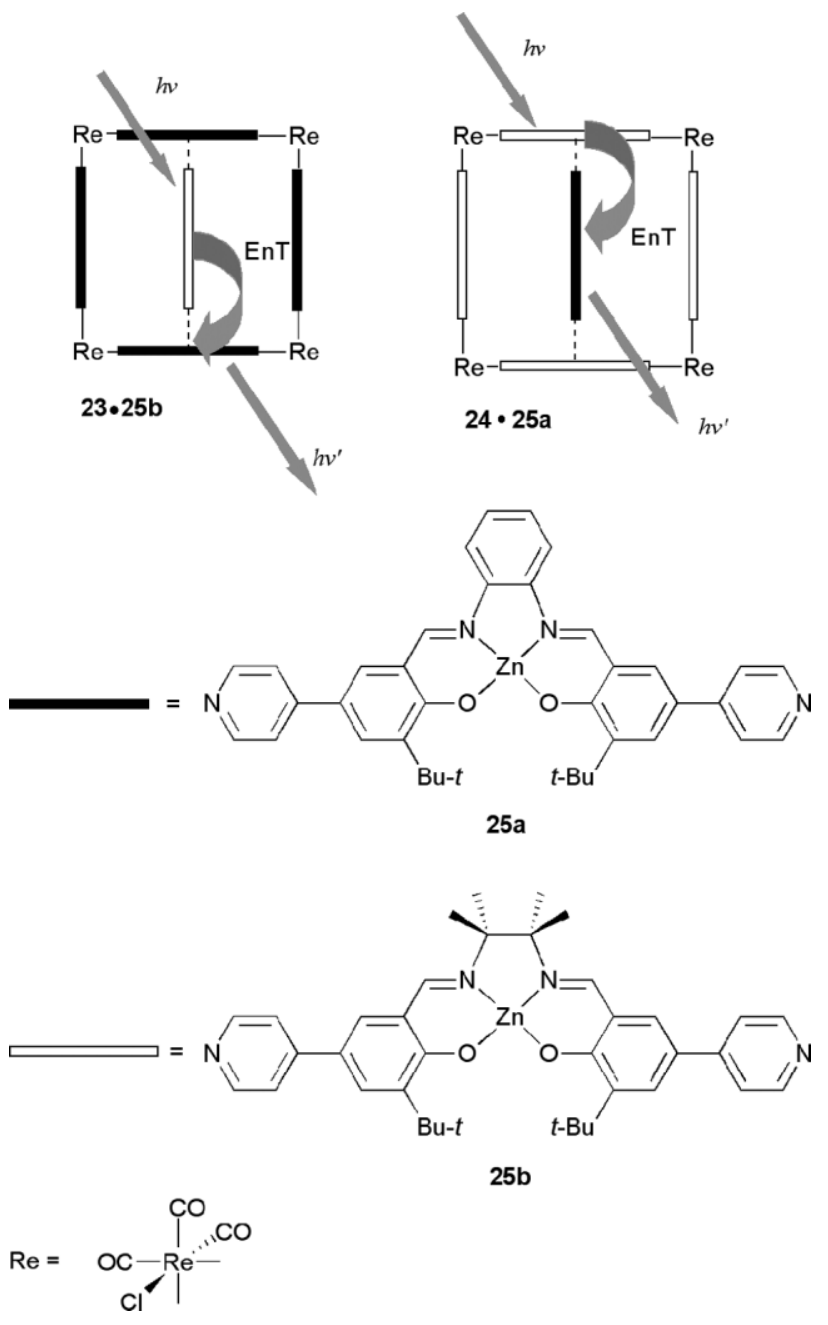

Fig. 11 Energy transfer reactions for pentakis(salen) assemblies 23.25b and 24.25a.

( $\mathrm{R}=$ phenyl (acceptor, a), alkyl (donor, $\mathbf{b})$ ) the direction of energy transfer could be controlled within the supramolecular assembly, i.e. in host-guest complex $\mathbf{2 3} \cdot \mathbf{2 5} \mathbf{b}$ the guest salen transferred energy to the host, while in the reversed host-guest complex 24.25a the salen walls acted as antennae and transferred their energy to the encapsulated guest (outside-to-inside energy transfer). The possibility of energy transfer within one macrocycle was also demonstrated for a $\mathrm{Re}^{\mathrm{I}}$ ion bridged porphyrin dyad with both a 21-thia and a 21-oxaporphyrin unit. ${ }^{31}$

In contrast to rhenium macrocycles that display luminescence in solution, Sullivan and co-workers reported rhenium-based rectangles with $\eta^{2}$-alkoxy or $\eta^{2}$-hydroxy bridges (26a-d) that only showed luminescence in the solid state, which was ascribed to the enhanced nonradiative decay via a torsional motion about the bipyridine bridge. ${ }^{32}$

Luminescent mixed-metallic structures, such as the rheniumbased squares with terpy-bridging ligands (27), have also been prepared. ${ }^{33}$ The osmium complex 27a was highly luminescent at room temperature in solution, whereas the iron and ruthenium derivatives $\mathbf{2 7 b}$ and $\mathbf{2 7 c}$ were not. The emission intensity and position of $\mathbf{2 7}$ a were similar to those of the free osmium-compound ligand and was thus not influenced by the corner chromophores.

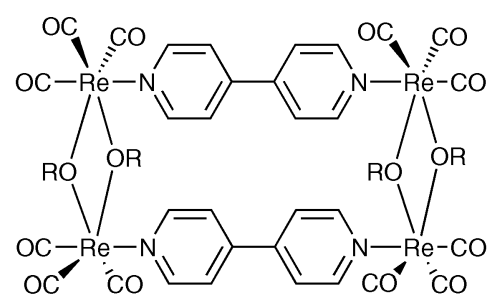

26

$\mathrm{R}=\mathrm{H}(\mathbf{a}), \mathrm{CH}_{3}(\mathbf{b}), \mathrm{CH}_{2} \mathrm{CH}_{3}(\mathbf{c}), \mathrm{CH}_{2} \mathrm{CH}_{2} \mathrm{OH}$ (d)

The lack of luminescence of $\mathbf{2 7} \mathbf{b}$ and $27 \mathbf{c}$ was attributed to an efficient non-radiative decay pathway between the metal-toligand charge transfer (MLCT) states and low-lying non-emissive metal-centered (MC) states. The square complexes exhibited multi-electron redox processes, which is further elaborated in the paragraph on Redox activity. A decrease in luminescence (25-fold) was also observed for a mixed metallic palladium-rhenium square, which was attributed to quenching by the palladium fragments. ${ }^{34}$

Lanthanide-ruthenium molecular squares 29a-c reported by Duan and co-workers exhibited near-infrared emission. ${ }^{35}$ The luminescence intensity of 29c was ten times higher than that of 29a and it was suggested that the lower luminescence intensity of 29a was a consequence of energy transfer from the rutheniumbipyridine triplet state to the excited state of the neodymium(III) center. The energy-transfer processes most likely involved an electron exchange mechanism that required considerable overlap between the $4 \mathrm{f}$ orbitals of the lanthanide ions and the ground state HOMO and LUMO of the functionalized ruthenium-bipyridine antenna chromophore.

Neutral molecular squares with metal-carbon bonds (30a-c) were also found to exhibit luminescence. ${ }^{36}$ Squares 30a-c displayed emission near $425 \mathrm{~nm}$, which emanated from the BINOL-ligands. The observed subnanosecond fluorescence decay times $(<400 \mathrm{ps})$ and low quantum efficiencies $\left(\Phi_{\mathrm{f}} \sim 0.02\right)$ suggested a rapid and efficient singlet-to-triplet intersystem crossing that was assisted by the presence of heavy $\mathrm{Pt}^{\mathrm{II}}$ atoms. Phosphorescence was not observed for the cycles. These chiral squares exhibited interesting dual luminescence and are, therefore, potentially exploitable as chiral sensory materials.

The observed luminescence for these different architectures provides a tag for sensory applications. An example of chiral sensing has been demonstrated by Lin and co-workers for a rhenium-based BINOL derived molecular square and is described in paragraph 3.2 , Sensing. ${ }^{37}$

Würthner and co-workers reported a series of luminescent platinum(II) and palladium(II) molecular squares, based on perylene tetracarboxylic acid bisimide ligands (31 and 32). ${ }^{38}$ The optical and electrochemical properties of the perylene ligands in platinum complexes 31a and 32 were completely conserved in the metalassembled state. Also for the palladium analog 31b fluorescence quenching by the metal ions was found to be negligible (quantum yields $\Phi_{\mathrm{f}}=0.88$ for 31a and 32, 0.86 for 31b and 0.94 for free perylene ligands). Similar behavior was reported by Lin and coworkers for self-assembled platinum and palladium macrocycles. ${ }^{39}$ Upon using pyrene-substituted perylene ligands, molecular square 33, which exhibited an intense red fluorescence, was obtained. ${ }^{40}$ Upon photoexcitation a fast $\left(k_{\mathrm{en}}=5.0 \times 10^{9} \mathrm{~s}^{-1}\right)$ and very efficient $(90 \%)$ energy transfer process from the outer pyrenes to the inner 


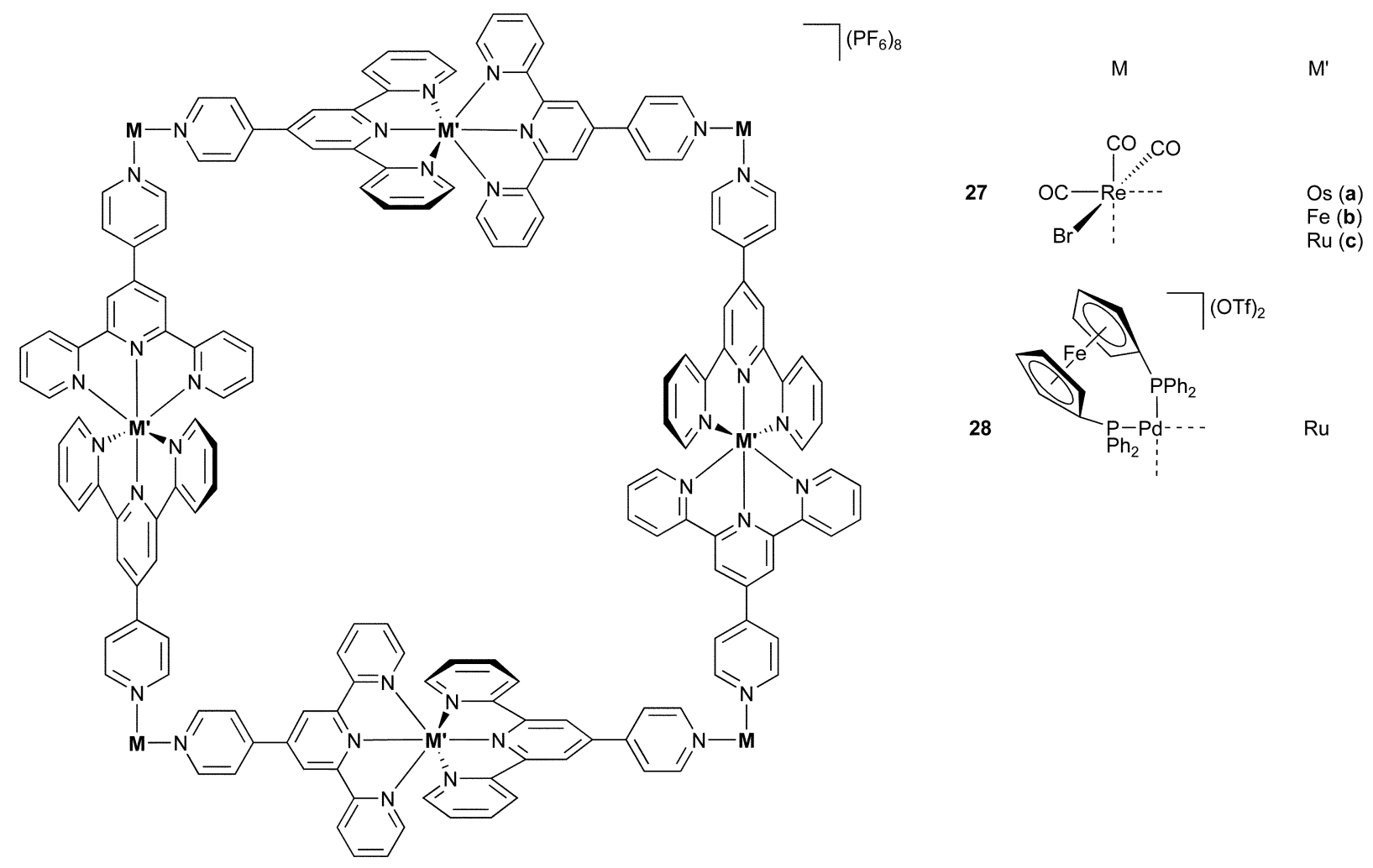

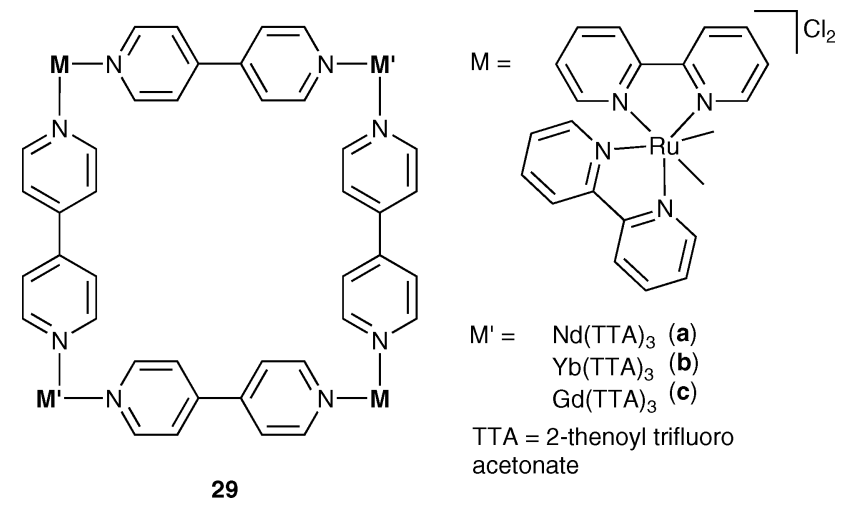

perylene dyes was observed, as well as a very fast and efficient ( $>94 \%$ ) electron-transfer process. However, competitive photoinduced electron-transfer processes thwarted the overall efficiency by a significantly reduced intensity of the pyrene bands $(50 \%)$. This kind of complex is reminiscent of the cyclic dye assemblies of light-harvesting bacteria, where the energy transfer from outer antenna dyes to the reaction center is essential for the efficient capture of sunlight.

\subsection{Redox activity}

Besides showing photoluminescence upon excitation, the metallasupramolecular architectures can also be redox active. ${ }^{25}$ Only a few redox active architectures have been reported, for example a recently reported triangular ruthenium-terpyridinebased macrocycle ${ }^{41}$ and complexes 31a and 32 described above, in which all four perylene units could be oxidized reversibly and independently, whereas the platinum corners appeared to

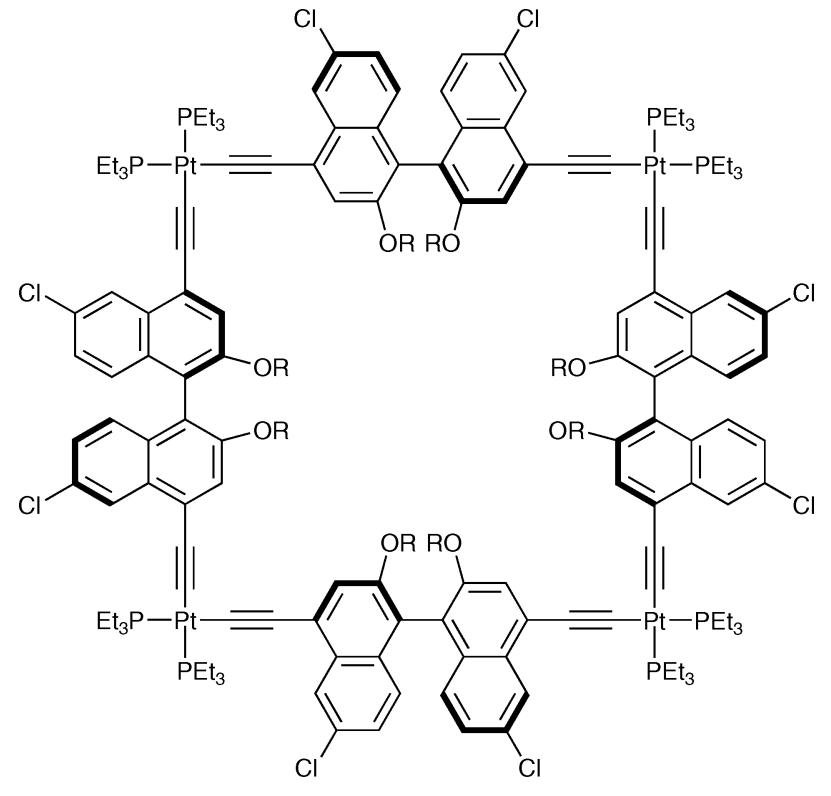

30

be electrochemically inert. ${ }^{38}$ In some cases the bridging ligands could be reversibly reduced and oxidized, without affecting the metals present, whereas in other structures the metal centers were oxidized/reduced. In these architectures the reduction/oxidation often occurred stepwise, an interesting feature, which is not observed for the free complexes. ${ }^{42}$

The molecular rectangle 34 (Fig. 12) was found to be an electron reservoir, i.e. the $\pi$-conjugated ligand components could be charged reversibly in a stepwise fashion with up to eight electrons, while the rhenium atoms were unaffected. ${ }^{43}$ 


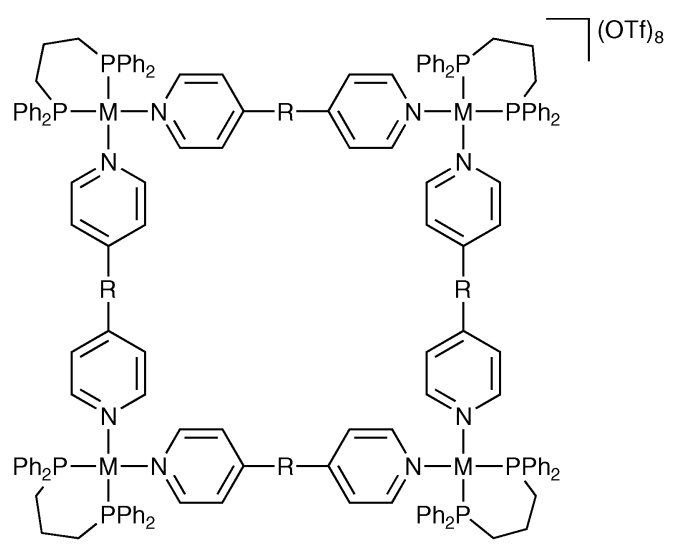<smiles>[R]c1cc2c3c(cc([R])c4c5c([R])cc6c7c(cc([R])c(c1c34)c75)C(=O)N(C)C6=O)C(=O)N(C)C2=O</smiles>

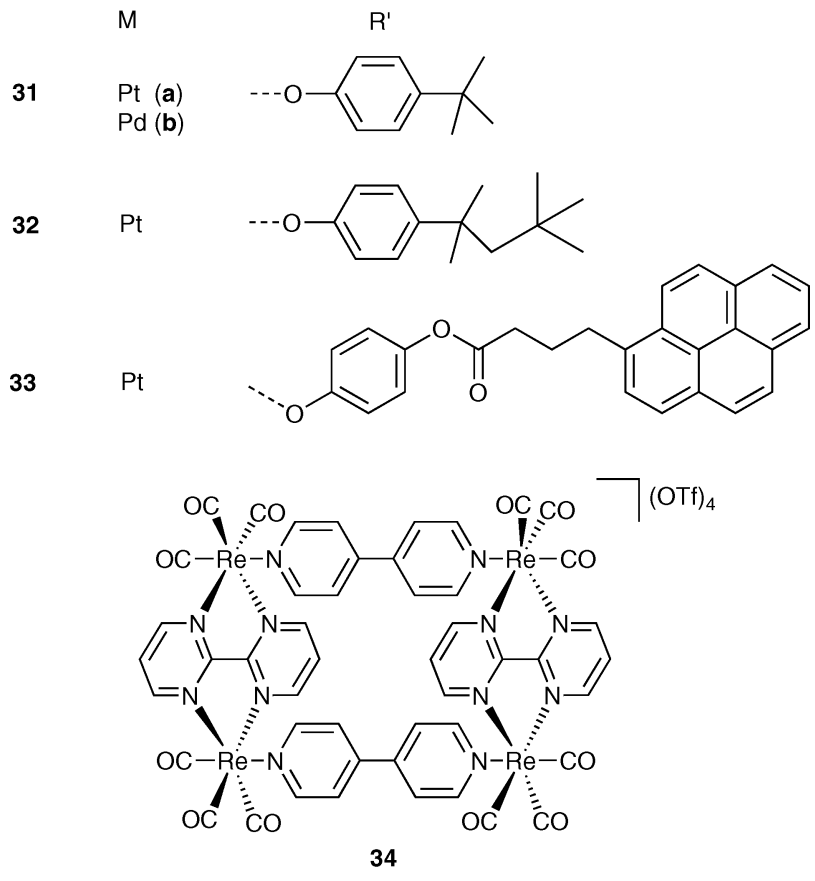

\section{Redox reaction}

$\left[\operatorname{Re}_{4}^{\prime}(\mathrm{bp})_{2}(\mathrm{bpym})_{2}(\mathrm{OC})_{12}\right]^{4+} \frac{+8 \mathrm{e}^{-}}{-8 \mathrm{e}^{-}}\left[\operatorname{Re}_{4}{ }^{\prime}\left(\mathrm{bp}^{2-}\right)_{2}\left(\mathrm{bpym}^{2-}\right)_{2}(\mathrm{OC})_{12}\right]^{4-}$

bpym $=$<smiles>c1cnc(-c2ncccn2)nc1</smiles>

Fig. 12 Molecular rectangle 34 and its redox reaction.

Reversible reduction of self-assembled cationic rectangles was found for 35 and 36 (Fig. 13), first in a two-electron process and then via two separated one-electron steps. ${ }^{44}$ Oxidation was also possible at rather low potentials in a reversible two-electron step, followed by an electrochemically irreversible process. This

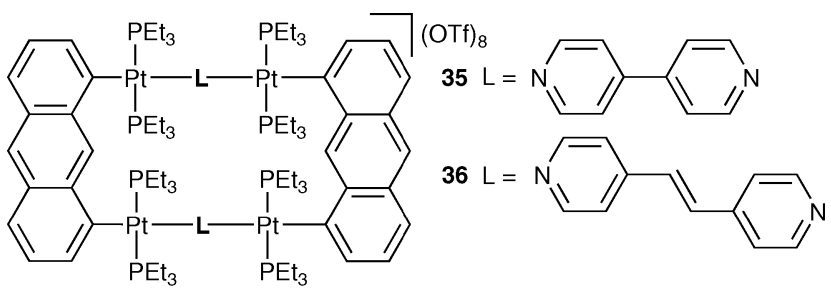

Redox reaction

$\left[\mathrm{Pt}_{4}{ }^{\prime \prime}\left(\mathrm{PEt}_{3}\right)_{8}(\text { anthr })_{2}(\mathrm{~L})_{2}\right]^{4+} \frac{+4 \mathrm{e}^{-}}{-4 \mathrm{e}^{-}}\left[\mathrm{Pt}_{4}{ }^{\prime \prime}\left(\mathrm{PEt}_{3}\right)_{8}\left(\mathrm{anthr}^{2-}\right)_{2}\left(\mathrm{~L}^{2-}\right)_{2}\right]$

Fig. 13 Molecular rectangles $\mathbf{3 5}$ and $\mathbf{3 6}$ and their redox reactions.

indicates that reduction occurred at the neutral acceptor ligands and that the oxidation took place at the formally dianionic anthracene moiety. The anionic units provided the chemical stability necessary for multiple reversible redox processes. The absence of such anionic units resulted in an irreversible electron transfer, as observed for self-assembled molecular square $\left[\operatorname{Pt}(\mathrm{dppp})\left(4,4^{\prime}-\right.\right.$ bipy) $]_{4}(\mathrm{OTf})_{8} \cdot{ }^{45}$

In addition to reversible reduction, reversible oxidation of supramolecular architectures has also been observed. Cyclic voltammetry studies showed that in each of the rhenium-based molecular squares with terpy-metal-bridging ligands $27 \mathbf{a}-\mathbf{c}$ and in the palladium-ruthenium analog $\mathbf{2 8}$, the divalent metal centers $(\mathrm{M}=\mathrm{Fe}, \mathrm{Ru}, \mathrm{Os})$ were simultaneously and reversibly oxidized to the trivalent state. ${ }^{33}$ An additional irreversible oxidation wave appeared for $\mathbf{2 8}$, which was assigned to the $\mathrm{Fc}^{+1 /+2}$ couple. In this heterometallic system, no recognizable communication between the metal centers could be observed. For the complexes two reductions were observed that were assigned to ligand-based reductions. The reduction potentials also exhibited multi-electrontransfer processes similar to the oxidation processes.

Contrary to the aforementioned examples, communication between metal centers was observed for the molecular square 37, as reported by Grimes and co-workers. ${ }^{46 a}$ This square is a neutral complex containing cobaltocarborane corners linked by diethynyl linkers. It revealed two separate one-electron reductions followed by a single two-electron reduction. This observation indicated the existence of significant intramolecular electronic communication between the four cobalt centers. The related molecular cage 38, displayed two separate, chemically reversible reductions, as well as two irreversible oxidations. ${ }^{46}$ Here, the intramolecular electronic communication essentially arose from the coupling of Co-centers within the linear Co-butadienyl-Co type moiety, whereas the trienyl-benzene linkages connecting these units had almost no effect.

An example of oxidation of both the ligands and the metal centers is presented by the ruthenium(II) porphyrin tetramers $\left[\mathrm{Ru}\left(4-\mathrm{PyP}_{3}\right) \mathrm{L}\right]_{4} 39$ of Imamura and co-workers. ${ }^{47}$ Complexes 39a and 39b showed first stepwise oxidation at the porphyrin rings, while for 39c the first stepwise four-electron oxidation occurred at the central ruthenium ions. The results demonstrated the presence of excitonic interactions between the ruthenium porphyrin subunits in the tetramer frameworks.

The combination of the electroactivity and the complexation features of these metallasupramolecular architectures as described could lead to attractive sensory materials. This subject will be dealt with in section 3.2 . 

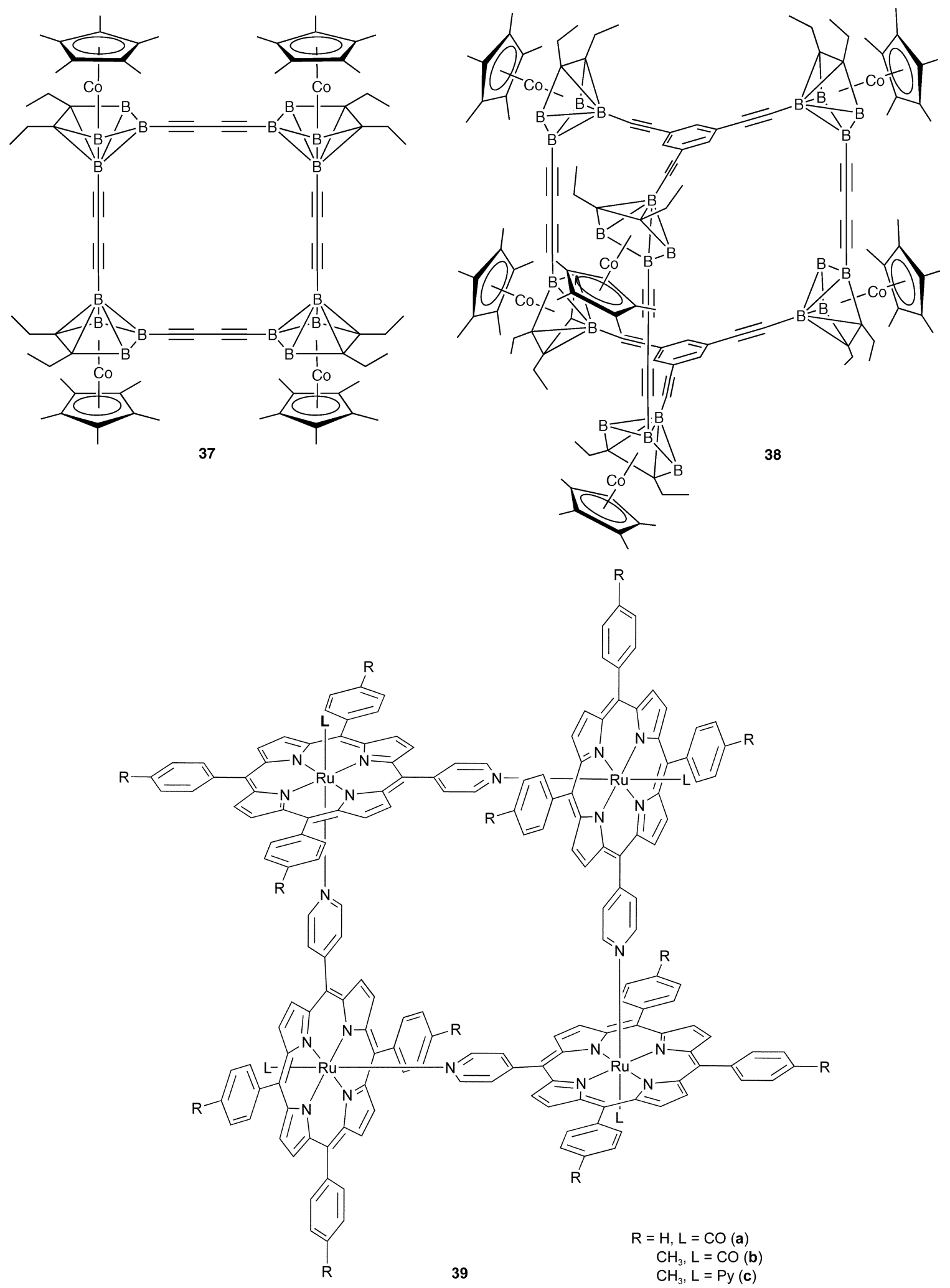

\subsection{Magnetic behavior}

Although many self-assembled oligonuclear complexes with paramagnetic transition metals are reported as single molecule magnets ${ }^{48}$ only a few supramolecular architectures are known which exhibit ferromagnetic interactions. A nice example is the hexanuclear wheel-shaped complex $\mathbf{4 0}$, which forms honeycomblike channels (diameter $=11.5 \AA)$ in the solid state. ${ }^{49}$ This complex was found to exhibit ferromagnetic intermolecular interaction. Interestingly, the porous material was capable of encapsulation of alkali-metal chlorides, which resulted in an enhancement of the ferromagnetic interaction. ${ }^{49 c}$ This complex can therefore be 
regarded as an example of a porous solid utilized for chemically switchable magnetic materials.

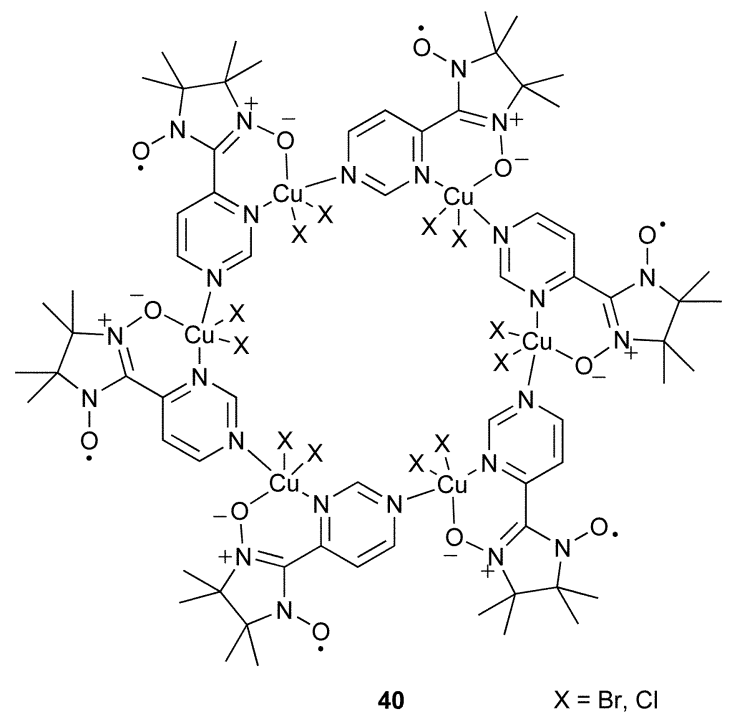

\section{Applications}

The supramolecular architectures have been applied in various fields of science and technology, by exploiting the presence of a cavity that allows for host-guest chemistry and the photoluminescent and electronic properties of these structures. A selection of the functional metallasupramolecular architectures and their applications are highlighted below.

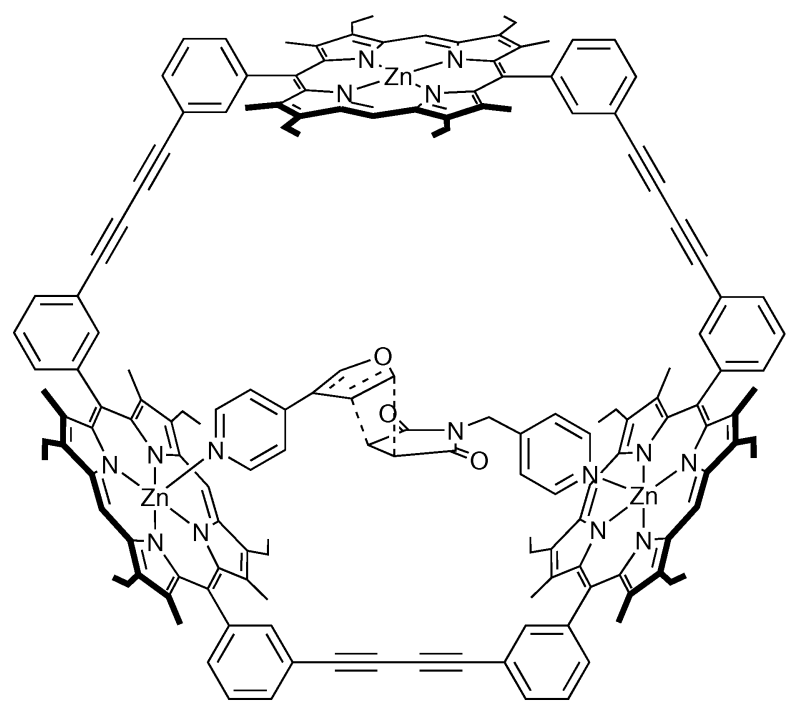

41•(G5+G6)

\subsection{Cavity-directed reactions and catalysis}

The possibility of performing organic reactions in the cavity of organic capsules has thoroughly been studied by Rebek et al. Large molecules were prepared, which dimerize in solution through a self-complementary system of hydrogen bonds to form closed-shell capsules of roughly spherical shape (soft-ball). The capsules could bind smaller molecules of complementary size and shape and were found to enhance Diels-Alder reactions through reversible encapsulation..$^{50}$ Nevertheless the number of reports, in which the cavities of metallasupramolecular structures have been used for organic reactions, remains limited. An example is the use of a covalently bound trimeric porphyrin host $\mathbf{4 1}$ (Fig. 14) as a template for the acceleration of the intramolecular Diels-Alder reaction of a furan-based diene and a maleimide-based dienophile. ${ }^{51}$ With one equivalent of trimer $\mathbf{4 1}$ the reaction rate was enhanced considerably, 200-fold increase of the initial forward rate, and only the formation of the exo-adduct was detected, whereas generally the reaction is reversible providing both the endo- as well as the exo-adducts. No acceleration was observed with the monomeric porphyrin, nor when the strong binding guest tripyridyltriazine, which blocked the active binding sites of 41, was added to the solution. Trimer $\mathbf{4 1}$ was also applied for the catalyzed acyl transfer reaction, for which a 16 -fold increase in reaction rate was found. ${ }^{52}$ The reaction proceeded through a tightly-bound intermediate, in which both the pyridyl ring and the imidazole group were coordinated to two of the $\mathrm{Zn}^{\mathrm{II}}$ centers within 41, bringing the reactive sites into close proximity.

Fujita has shown a versatile use of cages $\mathbf{1 2}$ and $\mathbf{4 2}$ for cavitydirected synthesis in numerous reports. For example the ship-ina-bottle synthesis of otherwise labile cyclic trimers of siloxanes

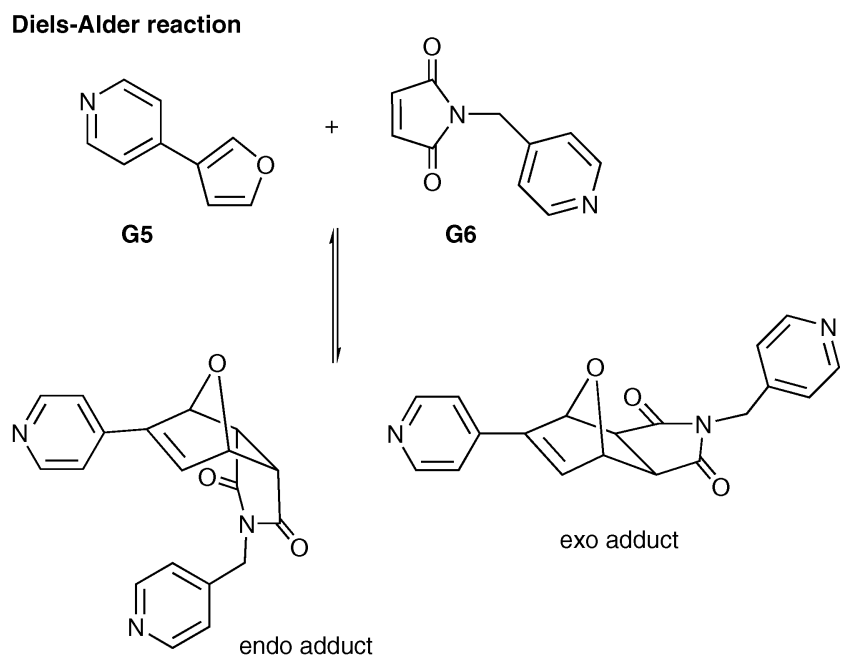

Acyl transfer reaction

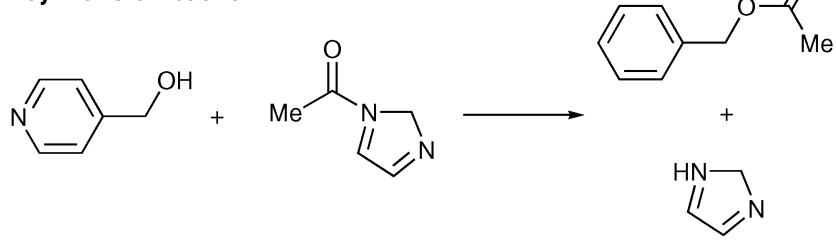

Fig. 14 Host $\mathbf{4 1}$ in proposed transition state for Diels-Alder reaction and the catalyzed Diels-Alder and acyl transfer reactions. 


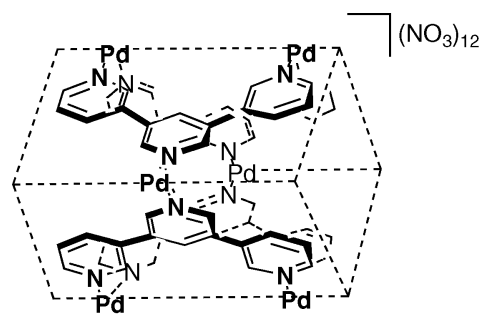

43

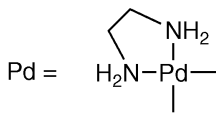

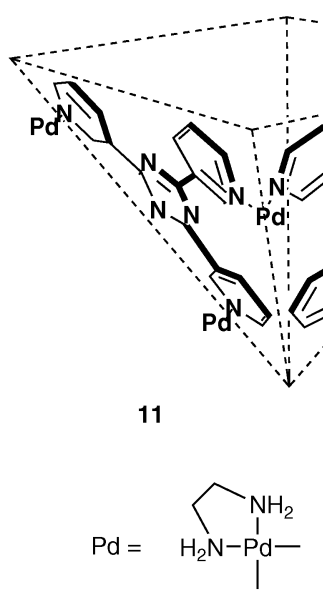

12 $P d=$
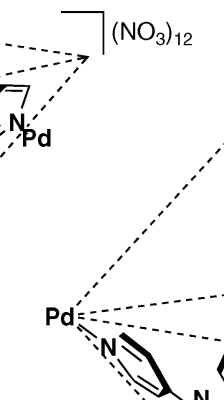

12<smiles>C1CCC2CCC2C1</smiles><smiles>CCN(C)O[Na]</smiles>
$\left(\mathrm{NO}_{3}\right)_{12}$

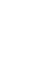
'́, $\therefore$

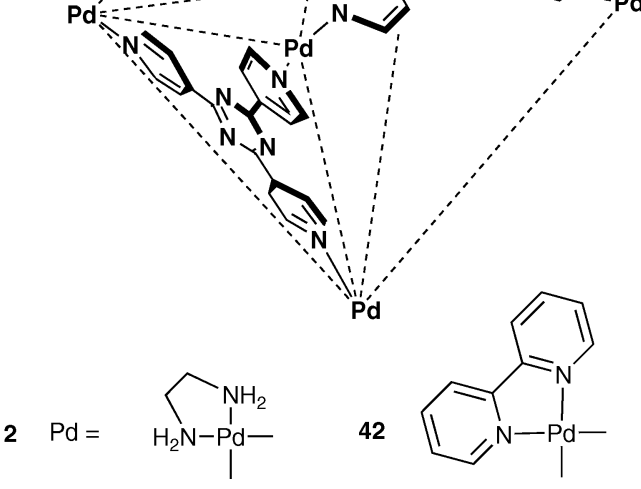

(G7, reaction A, Fig. 15). ${ }^{53}$ These trimers have never been isolated before, but they could be observed as stable molecules when the condensation reaction was carried out within the nanosized cavity of 42. Trialkoxysilanes could enter or exit through the portals of $\mathbf{4 2}$, but the formed cyclic trimers were no longer able to escape, as their dimension was larger than that of the portal size. The stereochemistry of the condensation reaction was highly controlled by the shape and the dimensions of the cage, giving cisisomers only. When cages of various sizes, i.e. small (43), medium (11) and large (12) were used for 2-naphthyltrimethoxysilane, a cavity-directed synthesis was observed. ${ }^{54}$ The reaction was controlled such by the size and shape of the cavities that their optimal guests were formed as products, i.e. cage $\mathbf{1 2}$ lead to the formation of the trisilanol $\mathbf{G 7}$, selective preparation of the silanol dimer $\mathbf{G 8}$ was accomplished using 11, but in the smaller cage $\mathbf{4 3}$ oligomerization was not observed (G9) (reaction A, Fig. 15).

Stereoselective cavity-directed synthesis was observed with cages $\mathbf{1 2}$ and $\mathbf{1 1}$ for the [2+2] photodimerization of olefins (acenaphthylenes, naphthoquinones) (reaction B, Fig. 15). ${ }^{55}$ Irradiation of 12 with two acenaphthalene molecules gave selectively syn-dimer, which could be isolated by extraction with $\mathrm{CHCl}_{3}$. Photodimerization of naphthoquinones was effectively controlled by bowl-shaped host 11, which led to the formation of synisomer in $>98 \%$ yield. Reactions in absence of the cages lead to poor stereoselectivities. In this photoreaction, the cage did not participate in the photochemical processes, but only provided a confined microspace to control the reactions.

In a recent publication it was shown that a photochemical reaction was sensitized by self-assembled cage 12. ${ }^{56}$ The cage was applied in alkane oxidation via photochemical excitation of the cage itself (reaction C, Fig. 15). The overall process involved: (1) encapsulation of adamantane in a 1:4 host-guest ratio, (2) photochemical excitation of the host framework at the triazine ligand under aerobic conditions, (3) electron-transfer from a close-contact adamantane guest to the cage host forming an 1adamantyl radical, and (4) subsequent regioselective oxidation of adamantyl at a tertiary carbon within the cavity, resulting in the formation of both 1-adamantylhydroperoxide and 1-adamantol. The host-guest complexation was essential as adamantane itself did not react in absence of $\mathbf{1 2}$ or in the presence of only the metal or the ligand component of $\mathbf{1 2}$. Large cyclic and linear alkanes were not accommodated by 12 and hence were not oxidized. Tight hostguest contacts were important, which was revealed when bowl $\mathbf{1 1}$ was applied in the same reactions. Bowl $\mathbf{1 1}$ was able to encapsulate alkane guests, but did not mediate the photoexcitation reaction under the same conditions.

Organic radicals G10, which have no particular intermolecular interactions when free in solution, showed cavity-induced spinspin interactions under encapsulation in cage $\mathbf{4 2}$, in a $1: 2$ hostguest ratio (reaction D, Fig. 15). ${ }^{57}$ The two radical centers of the guest were enforced in close contact with each other inside the cavity and as a result, the through-space intermolecular spin-spin interaction between the two radicals could be observed in solution by ESR.

Fujita and co-workers have used cage $\mathbf{1 2}$ also for the aerobic aqueous oxidation of styrene and its derivatives in $\mathrm{D}_{2} \mathrm{O}$ in the presence of extra $\left[\mathrm{Pd}\left(\mathrm{NO}_{3}\right)_{2}(\mathrm{en})\right]$ (Wacker oxidation, reaction $\mathrm{E}$, Fig. 15) ${ }^{58}$ The reaction was promoted by a double catalysis system, i.e. the cage acted as a reverse phase-transfer catalyst, whereas $[\operatorname{Pd}(\mathrm{en})]^{2+}$ was the oxidation catalyst. Styrene was partly transferred to the aqueous phase, forming 12.(styrene) ${ }_{n}$ clathrate complex $(n=c a$. 3), after which the styrene was oxidized to acetophenone by the catalyst. The formed acetophenone was replaced by the more hydrophobic, unreacted styrene. No reaction was observed in absence of either $\mathbf{1 2}$ or $\left[\mathrm{Pd}\left(\mathrm{NO}_{3}\right)_{2}(\mathrm{en})\right]$, or in the presence of 1,3,5-trimethoxybenzene, which has a much higher affinity for the cage than styrene.

Metallasupramolecular structures can also be used in enantioselective synthesis as was demonstrated by Lin and co-workers. They prepared the enantiopure chiral metallacyclophane $\mathbf{4 4}$, and used it in the asymmetric addition of diethylzinc to aromatic aldehydes (Fig. 16) ${ }^{59}$ The combination of $\mathbf{4 4}$ and $\left[\mathrm{Ti}\left(\mathrm{O}^{\prime} \mathrm{Pr}\right)_{4}\right]$ resulted in an excellent catalyst for the addition of diethylzinc to 1-naphthaldehyde with $94 \%$ ee and $>95 \%$ conversion at $0{ }^{\circ} \mathrm{C}$. When smaller aromatic 
A Cavity-directed oligomerization

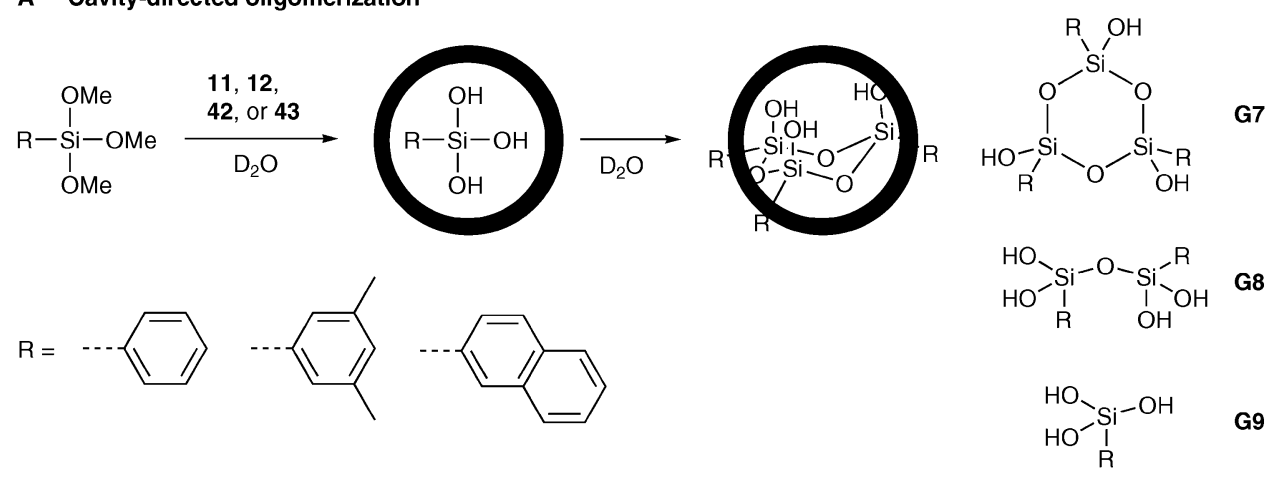

B Cavity-directed photodimerization

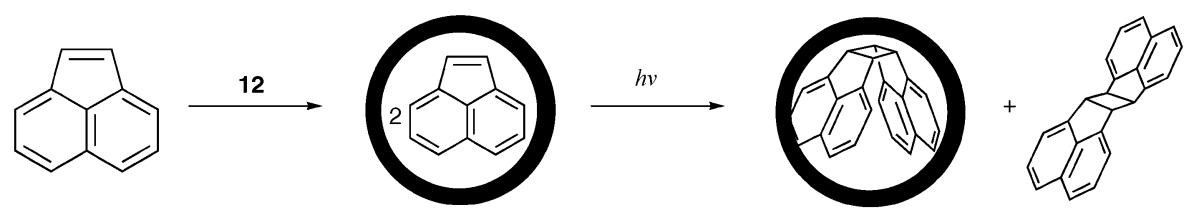

2

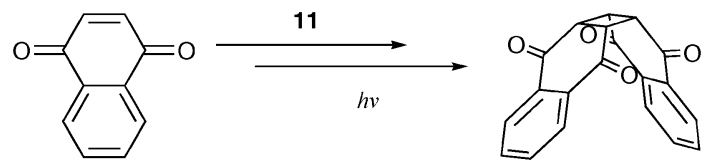

C Photochemical oxidation promoted by self-assembled cage

hv

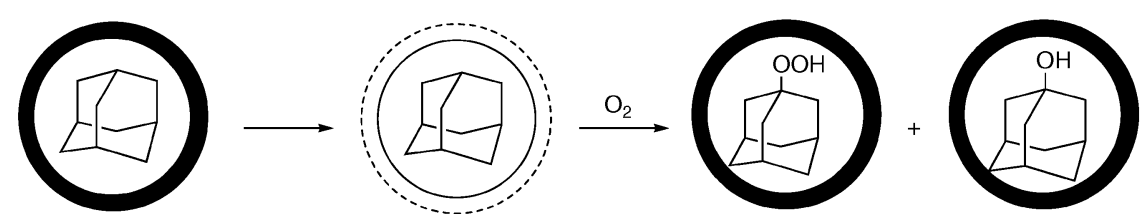

cage 12

D Cavity-induced spin-spin interaction

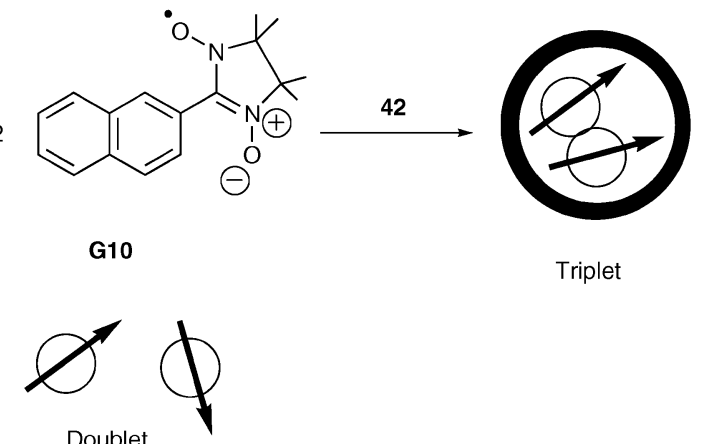

E Reversible-phase-transfer catalysis

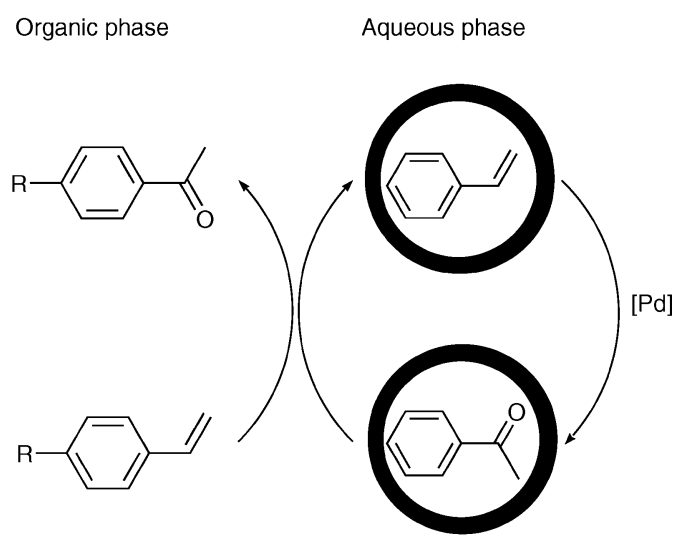

cage 12

Fig. 15 Cavity-directed reactions A-E with cages 11, 12, 42 and 43. 


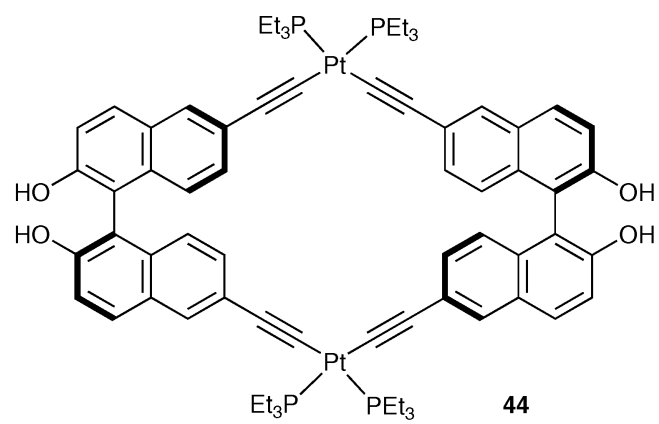

Reaction

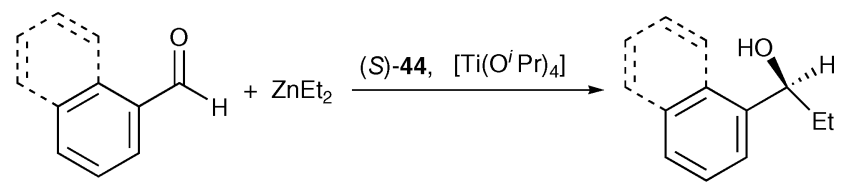

ee $(77-94 \%)$

Fig. 16 Cyclophane 44 and the catalyzed asymmetric reaction.

aldehydes were used, the enantioselectivity dropped significantly to $77-84 \%$ ee. This difference has been ascribed to the rigid structure of 44: the dihedral angles of the naphthyl rings in the $\mathrm{Ti}^{\mathrm{IV}}$ catalyst cannot vary when accommodating aldehydes of various sizes, which is required to produce high enantioselectivity. In this example, the catalyst was coordinated to the cyclophane and no catalytic activity was observed in the absence of the cage.

Hupp and co-workers encapsulated known active catalysts (e.g. $\mathrm{Mn}^{\mathrm{II}}$-porphyrins for epoxidation reactions, 45, 46, Fig. 17) in the supramolecular framework 13 (Fig. 8), which has been found to be an active host for porphyrins and other guests. ${ }^{19}$ Many olefinic substrates (e.g. styrene) could enter the cavity. Encapsulation of $\mathrm{Mn}^{\mathrm{II}}$ porphyrin 45 in a $1: 1$ host-guest ratio resulted in a tenfold increase in the turnover number (TON) $(c f$. TON $=$ 65 in case of the free catalyst), while the catalyst lifetime was extended from originally $10 \mathrm{~min}$ to $3 \mathrm{~h} .{ }^{60}$ Catalyst 46 was even more strongly bound in the cavity, greatly enhancing the TON to 1500. Further improvement of the TON to 21000 was observed by changing the host-guest ratio $13: 46$ to $1000: 1$. The rate of the reaction for the encapsulated catalysts was a factor of three slower than that observed for the free catalysts, which was ascribed to a hindered transport of reactants to the active site. This hypothesis was confirmed when using bulkier substrates $(\mathrm{R}=$ $t$ - $\mathrm{Bu}$ ), which resulted in a slow down of the rate of catalysis. The presence of additional ligands in the cavity, for example two molecules of 3,5-dinicotinic acid dineomentyl ester resulted in an even lower reactivity. Thus with the appropriate cavity functionalization, the catalyst can be designed such that partial or complete substrate exclusion or inclusion can be achieved. This system would therefore be able to perform selective catalysis.

Instead of encapsulation of a catalyst, supramolecular architectures themselves can also act as catalysts. This was demonstrated by Fujita and co-workers, who prepared a self-assembled molecular square network from $\left[\mathrm{Cd}\left(\mathrm{NO}_{3}\right)_{2}\right]$ and 4,4'-bipyridine, $\left\{\left[\mathrm{Cd}(\text { bpy })_{2}\right]\left(\mathrm{NO}_{3}\right)_{2}\right\}_{\infty}$ (47, Fig. 18). This compound was shown to be an active catalyst in the cyanosilylation of aldehydes and imines. ${ }^{61}$ Treatment of benzaldehyde with cyanotrimethylsilane in the presence of a suspension of 47 in $\mathrm{CH}_{2} \mathrm{Cl}_{2}$ gave 2(trimethylsiloxy)phenylacetonitrile in $77 \%$ yield. The reaction of imine with cyanotrimethylsilane under the same reaction conditions yielded $98 \%$ of aminonitrile. It was also found that the network acted as a heterogeneous catalyst, as reactions did not proceed with either 4,4'-bipyridine or $\left[\mathrm{Cd}\left(\mathrm{NO}_{3}\right)_{2}\right]$ alone, or with just the supernatant of the centrifuged catalyst suspension. Furthermore, a soluble model complex $\left[\mathrm{Cd}\left(\mathrm{Py}_{4}\right)\right]\left(\mathrm{NO}_{3}\right)_{2}$, which has partially the structure of $\mathbf{4 7}$, was found to promote the reactions less effectively. Shape specificity was observed when
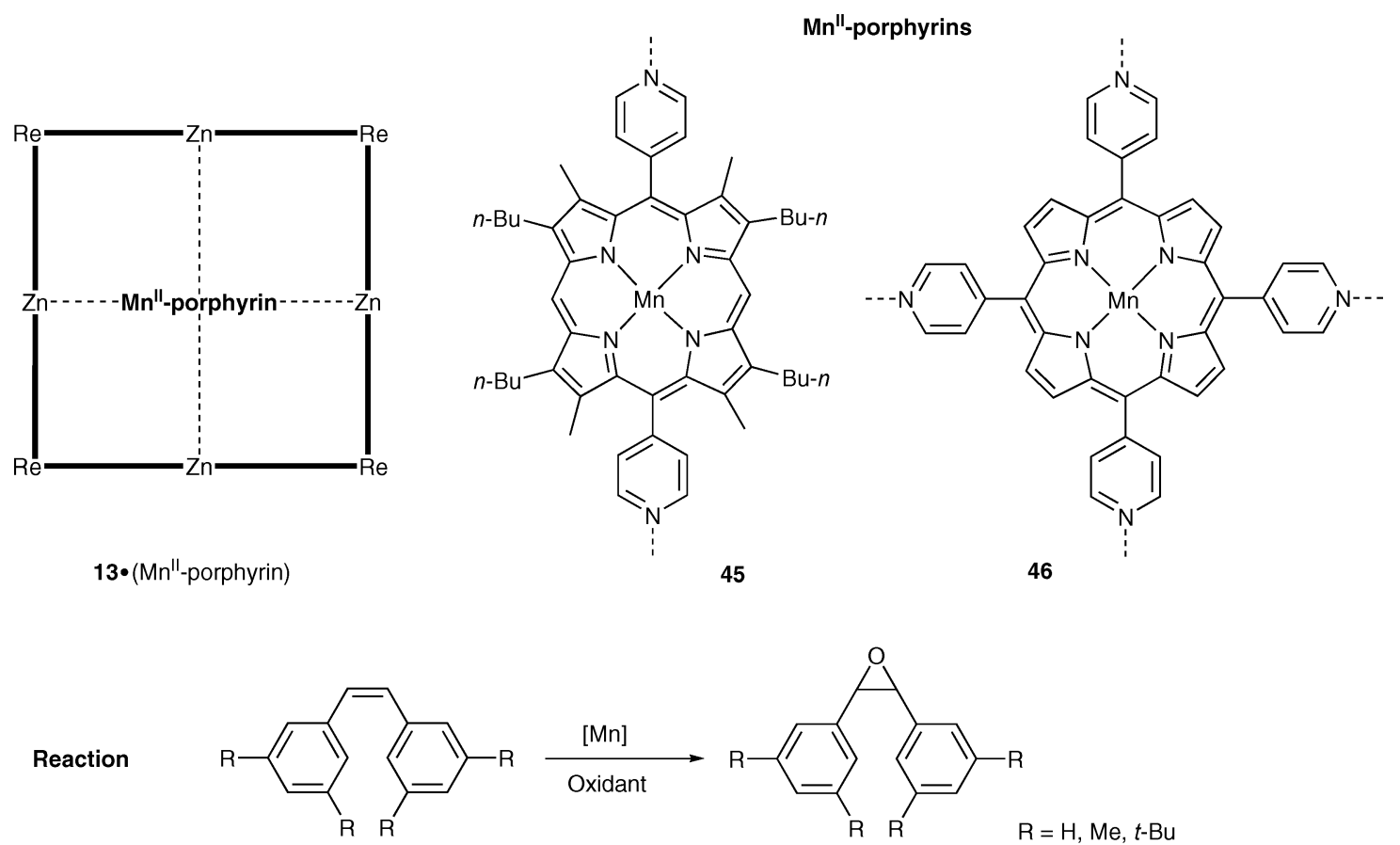

Fig. 17 Host 13 with encapsulated catalysts $\mathbf{4 5}$ and $\mathbf{4 6}$ and the catalyzed epoxidation reaction. 


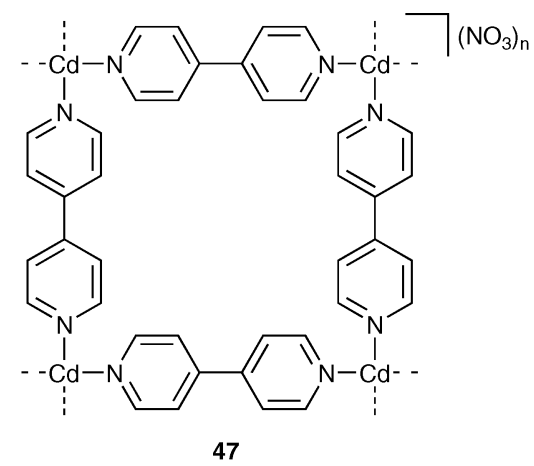

Reactions

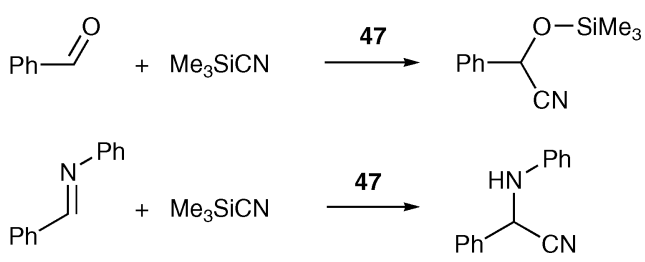

Fig. 18 Network 47 with the catalyzed reactions.

aldehydes with various sizes were used, i.e. larger substrates gave less conversion, which was ascribed to the distinct cavity size of the network material of $\mathbf{4 7}$.

The chiral tetranuclear cage $\mathbf{1 7}$ (Fig. 10) from Raymond and co-workers was able to act as a catalyst in a cationic 3-azaCope rearrangement. ${ }^{62}$ The reaction involved: (1) encapsulation of ammonium substrates $\mathbf{A}$ by the cage in a $1: 1$ ratio, (2) sigmatropic rearrangement to form an iminium cation, (3) subsequent hydrolysis to the corresponding aldehyde $\mathbf{B}$, and (4) release of the neutral product that was only weakly bound by the host (Fig. 19). Due to this weak binding, another substrate molecule could be encapsulated after the hydrolysis step, enabling a catalytic turnover. The reactivity of various substrates was tested for free and encapsulated ammonium cations and it was found that all substrates rearranged faster when encapsulated. For guests G1113 the largest accelerations upon encapsulation were observed, viz. 141, 150 and 854 times, respectively. The acceleration of the reaction was achieved because the substrates fitted tightly in the cavity, forcing the reactive sites into close proximity and thus decreasing the entropic barrier for rearrangement. Using small amounts of the catalyst, $13 \%$ relative to the substrate, the host

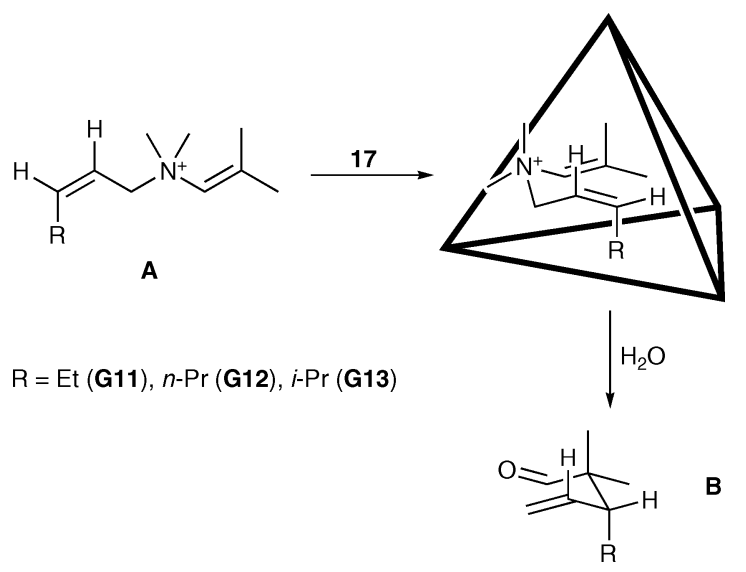

Fig. 19 Aza-Cope rearrangement reaction in cage 17. complex showed a catalytic behavior. Reaction enhancement due to the hydrophobic environment of the cage or the negative charge of the host was excluded by control experiments with various solvents and addition of salts.

The last example of the use of metallasupramolecular architectures in catalysis is the novel concept of signal amplification and detection via a metallasupramolecular allosteric catalyst for the acyl transfer reaction between acetic anhydride and pyridyl carbinol, by Mirkin and co-workers. ${ }^{63}$ In this approach the macrocyclic cavity of self-assembled compound 48 (with two structural domains containing $\mathrm{Rh}^{\mathrm{I}}$ centers and a catalytic domain containing two $\mathrm{Zn}^{\mathrm{II}}$ metal centers) acted as a sensor for the analyte $\mathrm{CO}$ in the presence of $\mathrm{Cl}^{-}$ions (Fig. 20). By introduction of $\mathrm{CO} / \mathrm{Cl}^{-}$complex 48 opened to form 49 ("switch on" reaction). The result of the selective breaking of the thioether/ $\mathrm{Rh}^{\mathrm{I}}$ bonds was a concomitant, significant change in molecular shape. In complex 49, an acetic anhydride molecule was activated by one $\mathrm{Zn}^{\mathrm{II}}$-salen moiety while a pyridyl carbinol molecule was bound to the other $\mathrm{Zn}^{\mathrm{II}}$ center within the supramolecular cavity, bringing the reactants in close proximity. With this bimetallic reaction a significant increase in the rate of formation of the acylated product (up to 25-fold rate enhancement) was observed, when compared to a monometallic $\mathrm{Zn}^{\mathrm{II}}$-salen complex. A straightforward detection method for visually and spectrophotometrically monitoring the reaction was provided by using a $\mathrm{pH}$-sensitive fluorophore, (diethylamino)methylanthracene (signal amplification reaction), i.e. the formed acetic acid protonates the fluorophore and a highly fluorescent compound is formed.

In this system, the concepts sensing and catalysis are combined in an innovative way. Here compound $\mathbf{4 8}$ acted as the sensor, while complex 49 acted as the catalyst. Other metallasupramolecular architectures have also been reported to be active as sensor materials, and this will be described below.

\subsection{Sensing}

The combination of host-guest behavior of various cyclophanes with their luminescent or electronic properties, can be exploited for sensing purposes. For example, encapsulation of a guest can selectively change the luminescent or electronic characteristics of the host and this can, therefore, be used as an indication for the presence of guest molecules in solution. ${ }^{64}$ For instance rectangle 50 acted as a chromatic sensor that was sensitive to micromolar concentrations of $\mathrm{Ni}^{2+}, \mathrm{Cd}^{2+}$ and $\mathrm{Cr}^{3+} .{ }^{65}$ When a solution of $\mathbf{5 0}$ was treated with either $\left[\mathrm{Ni}\left(\mathrm{NO}_{3}\right)_{2}\right] \cdot 6 \mathrm{H}_{2} \mathrm{O},\left[\mathrm{Cd}\left(\mathrm{NO}_{3}\right)_{2}\right] \cdot 6 \mathrm{H}_{2} \mathrm{O}$ or $\left[\mathrm{Cr}\left(\mathrm{NO}_{3}\right)_{3}\right] \cdot 4 \mathrm{H}_{2} \mathrm{O}$, up to a $1: 1$ host-guest ratio, a change in the $\mathrm{UV}-\mathrm{Vis}$ spectrum was observed. However, no quantitative data about the shift are provided.

In contrast to the absorption characteristics of 50, changes in luminescence properties can also be used for the preparation of sensor materials, as was reported by Lin and coworkers. ${ }^{37}$ The luminescent, enantiopure, chiral rhenium-based squares $\left[\mathrm{ReCl}(\mathrm{CO})_{3} \mathrm{~L}\right]_{4}((R)-\mathbf{5 1}$ and $(S)-\mathbf{5 1}$, Fig. 21) were able to encapsulate chiral amino alcohols, which resulted in a chiralitybased quench of their luminescence. With Stern-Völmer plots the luminescence quenching was determined and for $(R)-51$ an enantioselectivity factor $k_{\mathrm{sv}}(R-S) / k_{\mathrm{sv}}(R-R)$ of 1.22 for luminescence quenching was found in favor of $(S)$-2-amino-1-propanol (Stern-Völmer quenching constant of $(R)-\mathbf{5 1}, k_{\mathrm{sv}}=7.35 \mathrm{M}^{-1}$ 


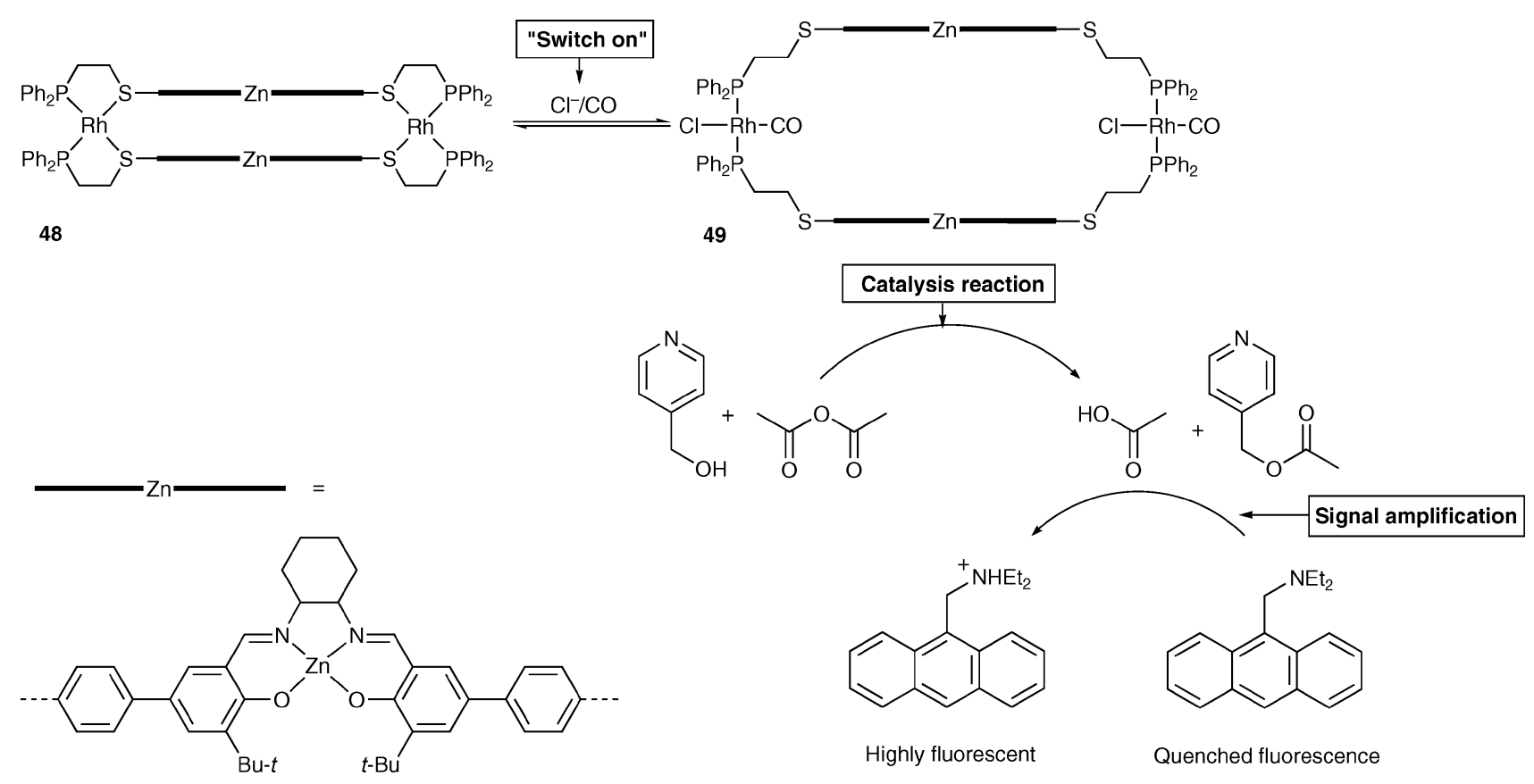

Fig. 20 Sensor $\mathbf{4 8}$ and catalyst $\mathbf{4 9}$ with the acyl transfer and signal amplification reactions.

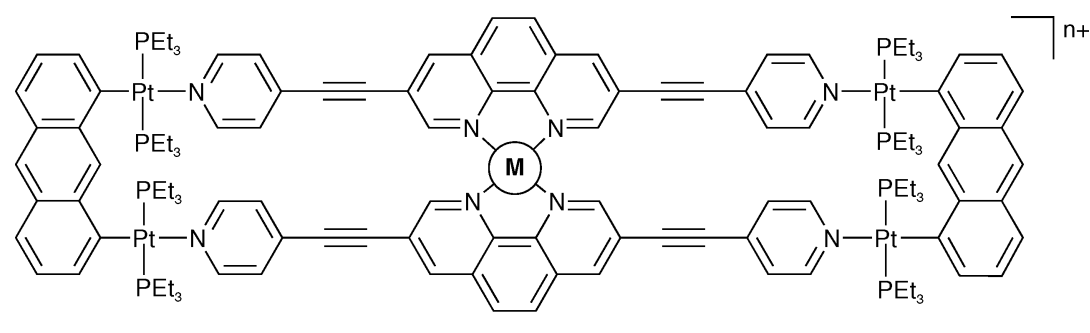

$50 \cdot$ metal cation

$\mathrm{M}=\mathrm{Ni}^{2+}, \mathrm{Cd}^{2+}, \mathrm{Cr}^{3+}$

and $6.02 \mathrm{M}^{-1}$ for $(S)$-2-amino-1-propanol and $(R)$-2-amino-1propanol, respectively). The opposite trend in enantioselectivity was observed for quenching of $(S)-51$ by the same molecule. It was also observed that the magnitude of enantioselectivity for square $\mathbf{5 1}$ was significantly higher than for the free ligand $\mathbf{L}$, which suggested that a better-defined chiral environment was conferred by metallacycle $\mathbf{5 1}$.

The sensing properties for the presence of volatile organic compounds (VOCs) of the self-assembled molecular rectangle 52a (Fig. 22) in the solid state were tested for thin, evaporativelycast films of 52a. ${ }^{66}$ The emission of the films was quenched upon exposure to $p$-toluidine vapor (which is a known reductor), but the emission was enhanced and shifted to higher energy when 52a was exposed to THF vapor. Quantitative assessments of VOC uptake could be achieved via quartz crystal microgravimetry (QCM) for thin-film arrays of a related manganese-based rectangle 52b and of molecular squares $\mathbf{2 0}$ and $\mathbf{2 1}$ when they were deposited on a quartz microbalance. ${ }^{6,67}$ The films exhibited a preference for aromatic guests (benzene) over aliphatic substrates (cyclohexane) and for good electron donors over poorer ones. This behavior did not depend on the metal used ( $\mathrm{Re}$ or $\mathrm{Mn}$ ). Size selectivity of the films was demonstrated with the uptake of cyclic ethers of various sizes, such as dioxane and the large 18-crown-6 cyclic ether (which is larger than the cavity of 20). This study showed that the amount of 18-crown-6 uptake was 1-2 orders of magnitude less than the amount of dioxane uptake (depending on film thickness). Regeneration of the films after VOC uptake was possible by placing the loaded films under vacuum at ambient temperature for $10 \mathrm{~min}$.

Next to the luminescent properties, the electronic behavior of host complexes can also be influenced by encapsulation of guests. The self-assembled dinuclear copper(II) metallamacrocycles $\mathbf{5 3}$ and 54 (Fig. 23) reported by Beer et al. were found to be redox active with quasi-reversible oxidation waves, but it was also found that binding of various anions in the metallamacrocycles resulted in a cathodic shifts in oxidation potentials of the hostguest complexes. ${ }^{68}$ Substantial cathodic shifts were observed for the larger cycle $\mathbf{5 4}$ in the presence of tetrahedral anions such as dihydrogenphosphate and perrhenate $(\sim 85 \mathrm{mV})$, whereas no significant perturbations were observed for chloride, bromide or nitrate anions. In contrast, the smaller macrocycle $\mathbf{5 3}$ exhibited a noticeable shift in case of chloride $(20 \mathrm{mV})$, but displayed 


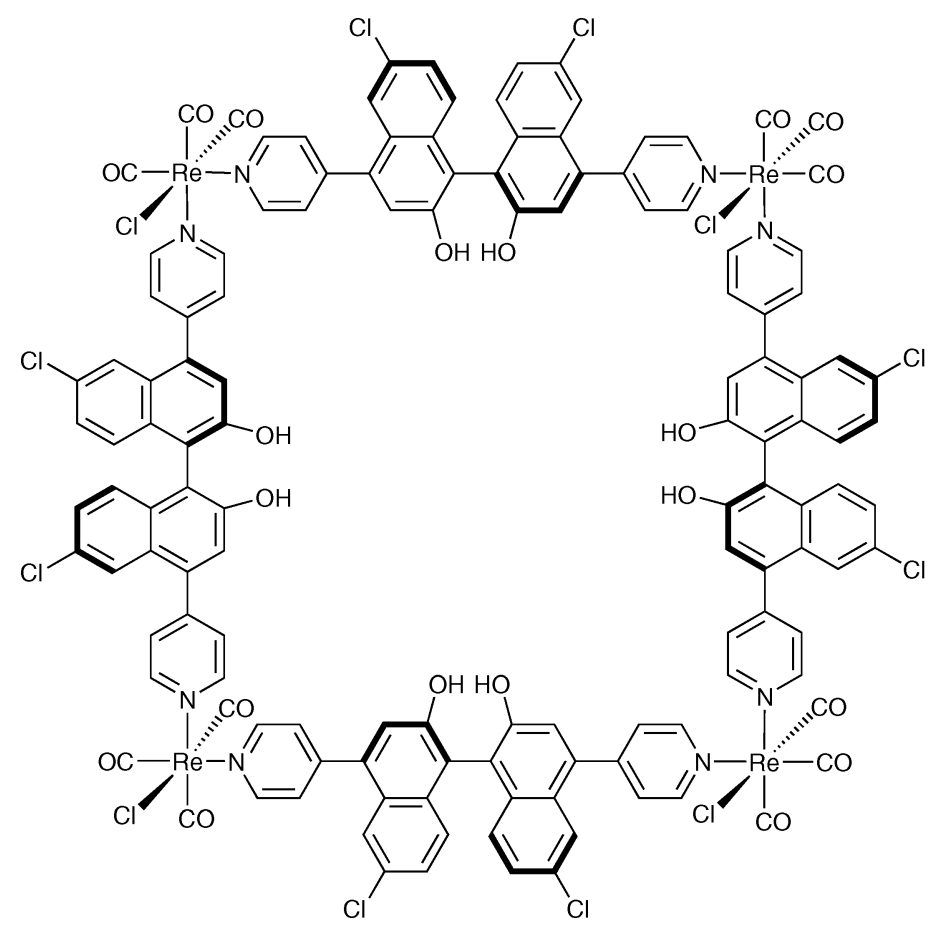

Substrate<smiles>C[C@@H](N)O</smiles>

(R)-2-amino-1-propanol

(S)-51

Fig. 21 Sensor (S)-51 and substrate molecule.

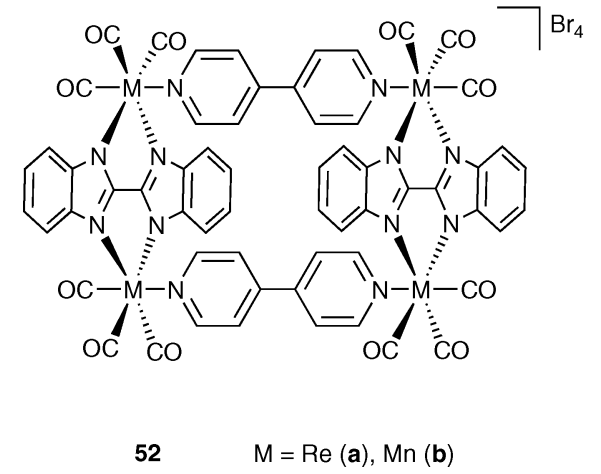

Fig. 22 Sensor $\mathbf{5 2}$ with substrates.

little response to the other larger anions. This indicated that these type of macromolecules are size-selective sensor materials. A cathodic shift was also reported for a self-assembled nickel-based metallacycle upon encapsulating $\mathrm{Mg}^{2+}$ ions in solution as well as in the solid state. ${ }^{69}$

The last example of the application of metallacyclophanes as sensors discussed here is the one reported by Lahav et al. The molecular square $\left[\mathrm{Pd}(\mathrm{en})\left(4,4^{\prime} \text {-bipy }\right)\right]_{4}\left(\mathrm{NO}_{3}\right)_{8}(\mathbf{1})^{4}$ was used to prepare gold-colloid-'molecular square' superstructures by crosslinking the positive molecular squares with negatively charged gold nanoparticles (Fig. 24) ${ }^{70}$ By stepwise treatment of the superstructures with a gold nanoparticle solution and $\mathbf{1}$, interfaces of a controllable number of layers were generated $(\mathrm{Au}: \mathrm{Pd}=$ 30 : 1 for five layers). Superstructure 55 acted as a $\pi$-acceptor receptor for complexation of $\pi$-donor substrates as was also found for the single molecular square $1 .^{4}$ Binding of substrate

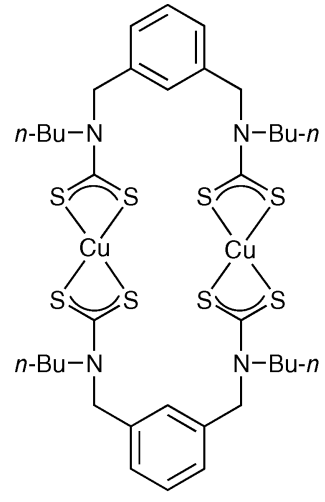

53

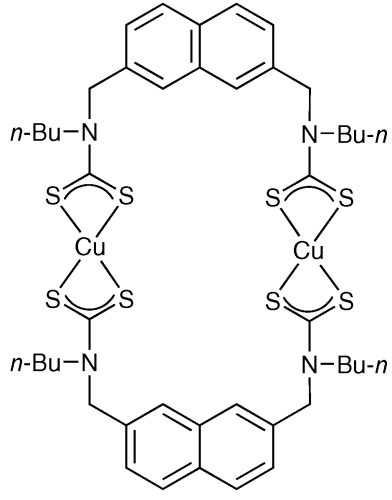

54

\section{Guest anions}

$\mathrm{Cl}^{-}, \mathrm{Br}^{-}, \mathrm{NO}_{3}^{-}, \mathrm{ReO}_{4}^{-}, \mathrm{H}_{2} \mathrm{PO}_{4}^{-}$

Fig. 23 Neutral sensors 53 and $\mathbf{5 4}$ and their guest anions.

$p$-hydroquinone $\left(1 \times 10^{-5} \mathrm{M}\right)$ to the receptor unit increased its local concentration at the electrode surface and, therefore, allowed its electrochemical sensing by the three-dimensional conductive Au-array, as monitored by cyclic voltammetry. It was found that the electrochemical response was enhanced upon increasing the number of layers.

\section{Concluding remarks}

Significant progress has been made in the past decade in the area of functional metallasupramolecular architectures. Their potential 

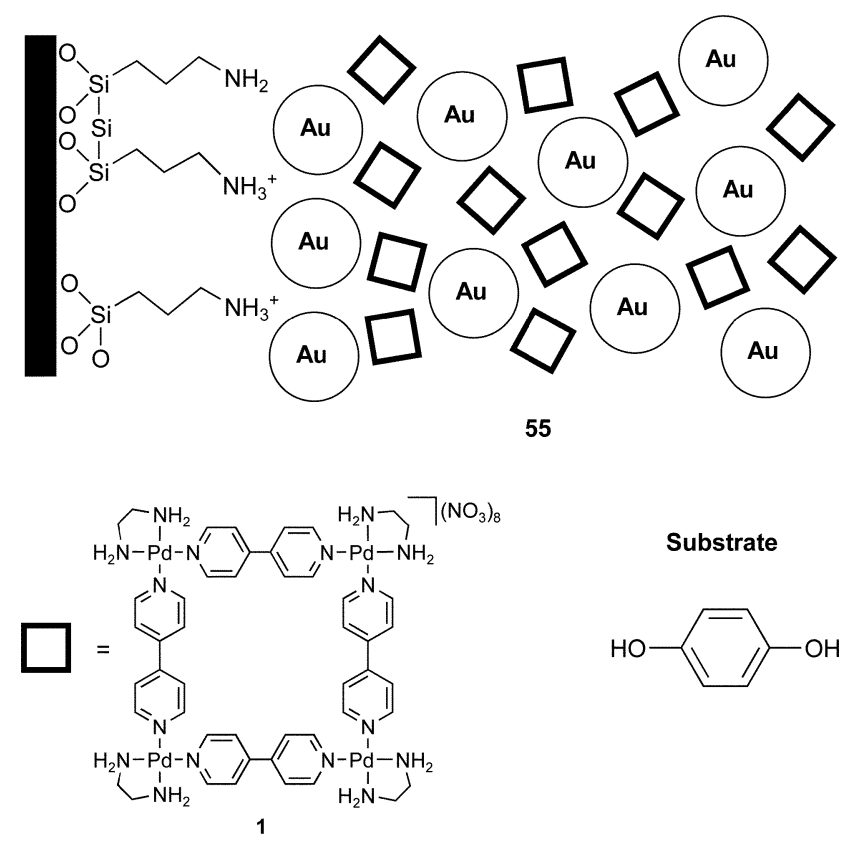

Fig. 24 Sensor 55 with substrate.

application as functional materials has been demonstrated in the fields of catalysis, cavity-directed synthesis and photo- and electrochemical sensing. These architectures can in some ways be linked to nature. They can for example be seen as artificial enzymes, i.e. the cavities can provide an induction of stability and selectivity toward substrates. In addition, the superstructures can protect the catalytic center from other reactive centers thereby enhancing the stability and lifetime of the catalytic center. Moreover, the possibility of energy transfer shows that these superstructures have resemblance to cyclic dye assemblies of light-harvesting bacteria for the capture of sunlight.

Nevertheless, considerable investigations still have to be carried out in this field, before these complexes actually can be applied. In the case of cavity-directed synthesis and catalysis, problems such as the removal of the products from the host material still have to be solved. In this context, an investigation of the mechanism of guest exchange in a supramolecular host was recently described by Raymond and co-workers. ${ }^{71}$ To arrive at viable applications for these supramolecular materials, a shift from a 1:1 host : guest ratio to much smaller ratios, i.e. to lower amounts of host, is also required. For the use of metallasupramolecular structures for sensing purposes, improved guest recognition and thus higher levels of guest specificity is essential. The development of new techniques for quantitative measurement of the uptake of guests, such as quartz crystal microgravimetry ${ }^{66,67}$ provide new opportunities for the exploitation of metallasupramolecular architectures in molecular devices.

\section{References}

1 (a) P. A. Chase, R. J. M. Klein Gebbink and G. van Koten, J. Organomet. Chem., 2004, 689, 4016-4054; (b) R. van Heerbeek, P. C. J. Kamer, P. W. N. M. van Leeuwen and J. N. H. Reek, Chem. Rev., 2002, 102, 3717-3756; (c) R. Kreiter, A. W. Kleij, R. J. M. Klein Gebbink and G. van Koten, Top. Curr. Chem., 2001, 217, 163-199; (d) M. A. Hearshaw and J. R. Moss, Chem. Commun., 1999, 1-8.
2 (a) S. Kitagawa, R. Kitaura and S. Noro, Angew. Chem., Int. Ed., 2004, 43, 2334-2375; (b) J. A. R. Navarro and B. Lippert, Coord. Chem. Rev, 2001, 222, 219-250; (c) P. J. Hagrman, D. Hagrman and J. Zubieta, Angew. Chem., Int. Ed., 1999, 38, 2638-2684; (d) B.-H. Ye, M.-L. Tong and X.-M. Chen, Coord. Chem. Rev., 2005, 249, 545-565.

3 (a) S. R. Seidel and P. J. Stang, Acc. Chem. Res., 2002, 35, 972-983; (b) M. Fujita, K. Umemoto, M. Yoshizawa, N. Fujita, T. Kusukawa and K. Biradha, Chem. Commun., 2001, 509-518; (c) B. J. Holliday, Angew. Chem., Int. Ed., 2001, 40, 2022-2043; (d) G. F. Swiegers and T. J. Malefetse, Chem. Rev., 2000, 100, 3483-3537; (e) C. J. Jones, Chem. Soc. Rev., 1998, 289-300.

4 M. Fujita, J. Yazaki and K. Ogura, J. Am. Chem. Soc., 1990, 112, $5645-5647$

5 (a) F. Würthner, C.-C. You and C. R. Saha-Möller, Chem. Soc. Rev., 2004, 33, 133-146; (b) A. Lützen, Angew. Chem., Int. Ed., 2005, 44, $1000-1002$.

6 A. W. Maverick, S. C. Buckingham, Q. Yao, J. R. Bradbury and G. G. Stanley, J. Am. Chem. Soc., 1986, 108, 7430-7431.

7 O. D. Fox, M. G. B. Drew, E. J. S. Wilkinson and P. D. Beer, Chem. Commun., 2000, 391-392.

8 R. P. Bonar-Law, L. G. Mackay and J. K. M. Sanders, J. Chem. Soc., Chem. Commun., 1993, 456-458.

9 Y.-Q. Chen, X.-Z. Wang, X.-B. Shao, J.-L. Hou, X.-Z. Chen, X.-K. Jiang and Z.-T. Li, Tetrahedron, 2004, 60, 10253-10260.

10 (a) K.-S. Jeong, Y. L. Cho, J. U. Song, H.-Y. Chang and M.-G. Choi, J. Am. Chem. Soc., 1998, 120, 10982-10983; (b) K.-S. Jeong, Y. L. Cho, S.-Y. Chang, T.-Y. Park and J. U. Song, J. Org. Chem., 1999, 64, 9459-9466.

11 M. Fujita, S. Nagao, M. Iida, K. Ogata and K. Ogura, J. Am. Chem. Soc., 1993, 115, 1574-1576.

12 S.-Y. Chang, M.-C. Um, H. Uh, H.-Y. Jang and K.-S. Jeong, Chem. Commun., 2003, 2026-2027.

13 (a) O. D. Fox, N. K. Dalley and R. G. Harrison, Inorg. Chem., 1999, 38, 5860-5863; (b) O. D. Fox, J. F.-Y. Leung, J. M. Hunter, N. K. Dalley and R. G. Harrison, Inorg. Chem., 2000, 39, 783-790.

14 M. Fujita, J. Yazaki and K. Ogura, Tetrahedron Lett., 1991, 32, 55895592.

15 J.-P. Bourgeois, M. Fujita, M. Kawano, S. Sakamoto and K. Yamaguchi, J. Am. Chem. Soc., 2003, 125, 9260-9261.

16 (a) S.-Y. Y. Yu, T. Kusukawa, K. Biradha and M. Fujita, J. Am. Chem. Soc., 2000, 122, 2665-2666; (b) T. Kusukawa and M. Fujita, Angew. Chem., Int. Ed., 1998, 37, 3142-3144.

17 S. Tashiro, M. Tominaga, M. Kawano, B. Therrien, T. Ozeki and M. Fujita, J. Am. Chem. Soc., 2005, 127, 4546-4547.

18 W.-Y. Sun, T. Kusukawa and M. Fujita, J. Am. Chem. Soc., 2002, 124, $11570-11571$.

19 S. Bélanger and J. T. Hupp, Angew. Chem., Int. Ed., 1999, 38, 2222 2224.

20 J. A. Whiteford, P. J. Stang and S. D. Huang, Inorg. Chem., 1998, 37, 5595-5601.

21 D. Fiedler, D. Pagliero, J. L. Brumaghim, R. G. Bergman and K. N. Raymond, Inorg. Chem., 2004, 43, 846-848.

22 (a) D. Fiedler, D. H. Leung, R. G. Bergman and K. N. Raymond, J. Am. Chem. Soc., 2004, 126, 3674-3675; (b) D. H. Leung, D. Fiedler, R. G. Bergman and K. N. Raymond, Angew. Chem., Int. Ed., 2004, 43, 963-696.

23 (a) M. Ziegler, J. L. Brumaghim and K. N. Raymond, Angew. Chem., Int. Ed, 2000, 39, 4119-4121; (b) J. L. Brumaghim, M. Michels and K. N. Raymond, Eur. J. Org. Chem., 2004, 4552-4559.

24 (a) C. M. Drain and J.-M. Lehn, J. Chem. Soc., Chem. Commun., 1994, 2313-2315; (b) J. Fan, J. A. Whiteford, B. Olenyuk, M. D. Levin, P. J. Stang and E. B. Fleischer, J. Am. Chem. Soc., 1999, 121, 2741-2742.

25 See for a review on metal-cyclophanes: R. V. Slone, K. D. Benkstein, S. Bélanger, J. T. Hupp, I. A. Guzei and A. L. Rheingold, Coord. Chem. Rev., 1998, 171, 221-243.

26 S. M. Woessner, J. B. Helms, J. F. Houlis and B. P. Sullivan, Inorg. Chem., 1999, 38, 4380-4381.

27 T. Rajendran, B. Manimaran, F.-Y. Lee, G.-H. Lee, S.-M. Peng, C. M. Wang and K.-L. Lu, Inorg. Chem., 2000, 39, 2016-2017.

28 S.-S. Sun and A. J. Lees, Inorg. Chem., 1999, 38, 4181-4182.

29 R. V. Slone, J. T. Hupp, C. L. Stern and T. E. Albrecht-Schmidt, Inorg. Chem., 1996, 35, 4096-4097.

30 K. E. Splan, A. M. Massari, G. A. Morris, S.-S. Sun, E. Reina, S. T. Nguyen and J. T. Hupp, Eur. J. Inorg. Chem., 2003, 2348-2351.

31 G. Santosh and M. Ravikanth, Inorg. Chim. Act., 2005, 358, 2671-2679. 
32 S. M. Woessner, J. B. Helms, Y. Shen and B. P. Sullivan, Inorg. Chem., 1998, 37, 5406-5407.

33 S.-S. Sun and A. J. Lees, Inorg. Chem., 2001, 40, 3154-3160.

34 R. V. Slone, D. I. Yoon, R. M. Calhoun and J. T. Hupp, J. Am. Chem. Soc., 1995, 117, 11813-11814.

35 D. Guo, C.-Y. Duan, F. Lu, Y. Hasegawa, Q.-J. Meng and S. Yanagida, Chem. Commun., 2004, 1486-1487.

36 S. J. Lee, C. R. Luman, F. N. Castellano and W. Lin, Chem. Commun., 2003, 2124-2125.

37 S. J. Lee and W. Lin, J. Am. Chem. Soc., 2002, 124, 4554-455.

38 (a) F. Würthner and A. Sautter, Chem. Commun., 2000, 445-446; (b) F. Würthner, A. Sautter, D. Schmid and P. J. A. Weber, Chem. Eur. J. 2001, 7, 894-902.

39 S. J. Lee, J. S. Kim and W. Lin, Inorg. Chem., 2004, 43, 6579-6588.

40 (a) F. Würthner and A. Sautter, Org. Biomol. Chem., 2003, 1, 240-243; (b) A. Sautter, B. K. Kaletas, D. G. Schmid, R. Dobrawa, M. Zimine, G. Jung, I. H. M. van Stokkum, L. De Cola, R. M. Williams and F. Würthner, J. Am. Chem. Soc., 2005, 127, 6719-6729.

41 S.-H. Hwang, C. N. Moorefield, F. R. Fronczek, O. Lukoyanova, L. Echegoyen and G. R. Newkome, Chem. Commun., 2005, 713-715.

42 F. A. Cotton, L. M. Daniels, C. Lin and C. A. Murillo, Chem. Commun., 1999, 841-842.

43 (a) H. Hartmann, S. Berger, R. Winter, J. Fiedler and W. Kaim, Inorg Chem., 2000, 39, 4977-4980; (b) K. D. Benkstein, J. T. Hupp and C. L. Stern, J. Am. Chem. Soc., 1998, 120, 12982-12983.

44 W. Kaim, B. Schwederski, A. Dogan, J. Fiedler, C. J. Keuhl and P. J. Stang, Inorg. Chem., 2002, 41, 4025-4028.

45 P. J. Stang and D. H. Cao, J. Am. Chem. Soc., 1994, 116, 4981-4982.

46 (a) H. Yao, M. Sabat, R. N. Grimes, F. Fabrizi de Biani and P. Zanello, Angew. Chem., Int. Ed., 2003, 42, 1002-1005; (b) F. Fabrizi de Biani, M. Corsini, P. Zanello, H. Yao, M. E. Bluhm and R. N. Grimes, J. Am Chem. Soc., 2004, 126, 11360-11369.

47 K. Funatsu, T. Imamura, A. Ichimura and Y. Sasaki, Inorg. Chem., 1998, 37, 1798-1804.

48 (a) S. Decurtins, R. Pellaux, G. Antorrena and F. Palacio, Coord. Chem Rev., 1999, 190-192, 841-854; (b) See special issue on Molecule-based Magnets, Polyhedron, 2003, 22, 1725-2584.

49 (a) J. Omata, T. Ishida, D. Hashizume, F. Iwasaki and T. Nogami, Inorg. Chem., 2001, 40, 3954-3958; (b) J. Omata, T. Ishida, D. Hashizume, F Iwasaki and T. Nogami, Polyhedron, 2001, 20, 1557-1561; (c) T. Ishida, J. Omata and T. Nogami, Polyhedron, 2003, 22, 2133-2138.

50 See for example(a) J. Kang and J. Rebek, Jr., Nature, 1997, 385, 50-52 (b) J. Kang, G. Hilmersson, J. Santamaria and J. Rebek, Jr., J. Am.
Chem. Soc., 1998, 120, 3650-3656; (c) J. Kang, J. Santamaria, G. Hilmersson and J. Rebek, Jr., J. Am. Chem. Soc., 1998, 120, 7389-7390.

51 C. J. Walter, H. L. Anderson and J. K. M. Sanders, J. Chem. Soc., Chem. Commun., 1993, 458-460.

52 L. G. Mackay, R. S. Wylie and J. K. M. Sanders, J. Am. Chem. Soc., 1994, 116, 3141-3142.

53 M. Yoshizawa, T. Kusukawa, M. Fujita and K. Yamaguchi, J. Am. Chem. Soc., 2000, 122, 6311-6312.

54 M. Yoshizawa, T. Kusukawa, M. Fujita, S. Sakamoto and K. Yamaguchi, J. Am. Chem. Soc., 2001, 123, 10454-10459.

55 M. Yoshizawa, Y. Takeyama, T. Kusukawa and M. Fujita, Angew. Chem., Int. Ed., 2002, 41, 1347-1349.

56 M. Yoshizawa, S. Miyagi, M. Kawano, K. Ishiguro and M. Fujita, J. Am. Chem. Soc., 2004, 126, 9172-9173.

57 K. Nakabayashi, M. Kawano, M. Yoshizawa, S.-I. Ohkoshi and M. Fujita, J. Am. Chem. Soc., 2004, 126, 16694-16695.

58 H. Ito, T. Kusukawa and M. Fujita, Chem. Lett., 2000, 598-599.

59 H. Jiang, A. Hu and W. Lin, Chem. Commun., 2003, 96-97.

60 M. L. Merlau, M. del Pilar Mejia, S. B. T. Nguyen and J. T. Hupp, Angew. Chem., Int. Ed., 2001, 40, 4239-4242.

61 (a) O. Ohmori and M. Fujita, Chem. Commun., 2004, 1586-1587; (b) M. Fujita, Y. J. Kwon, S. Washizu and K. Ogura, J. Am. Chem. Soc., 1994, 116, 1151-1152.

62 D. Fiedler, R. G. Bergman and K. N. Raymond, Angew. Chem., Int. Ed., 2004, 43, 6748-6751.

63 N. C. Gianneschi, S. T. Nguyen and C. A. Mirkin, J. Am. Chem. Soc., $2005,127,1644-1645$

64 For a review on luminescent sensor molecules, see: M. H. Keefe, K. D. Benkstein and J. T. Hupp, Coord. Chem. Rev., 2000, 205, 201-228.

65 M. J. E. Resendiz, J. C. Noveron, H. Disteldorf, S. Fischer and P. J. Stang, Org. Lett., 2004, 6, 651-653.

66 K. D. Benkstein, J. T. Hupp and C. L. Stern, Angew. Chem., Int. Ed., 2000, 39, 2891-2893.

67 M. H. Keefe, R. V. Slone, J. T. Hupp, K. F. Czaplewski, R. Q. Snurr and C. L. Stern, Langmuir, 2000, 16, 3964-3970.

68 P. D. Beer, N. Berry, M. G. B. Drew, D. Fox, M. E. Padilla-Tosta and S. Patell, Chem. Commun., 2001, 199-200.

69 M. Li, P. Cai, C. Duan, F. Lu, J. Xie and Q. Meng, Inorg. Chem., 2004, 43, 5174-5176.

70 M. Lahav, R. Gabai, A. N. Shipway and I. Willner, Chem. Commun., 1999, 1937-1938.

71 A. V. Davis and K. N. Raymond, J. Am. Chem. Soc., 2005, 127, 79127919. 